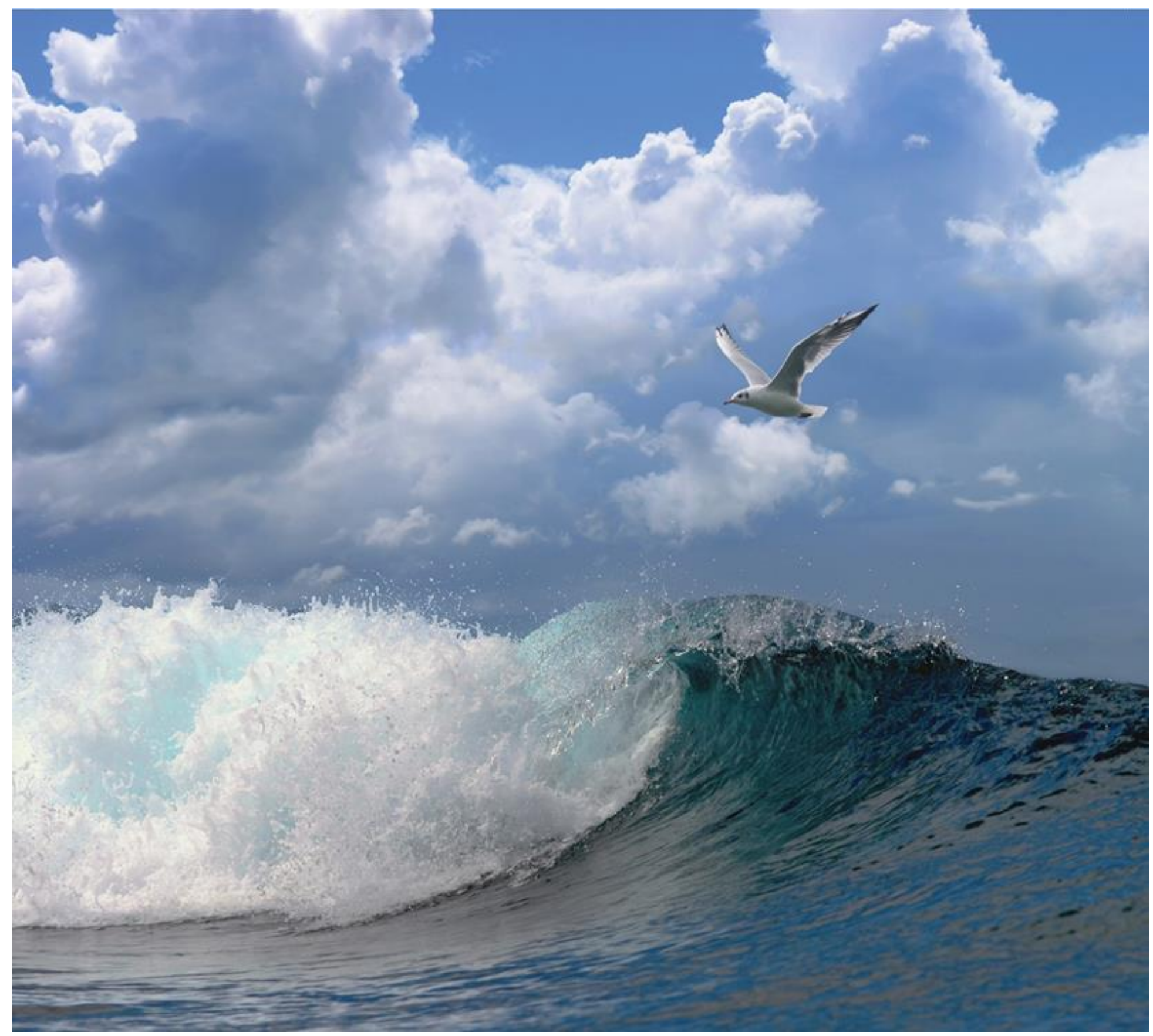

\title{
Schelpdierwateronderzoek 2016
}




\section{Schelpdierwateronderzoek 2016}

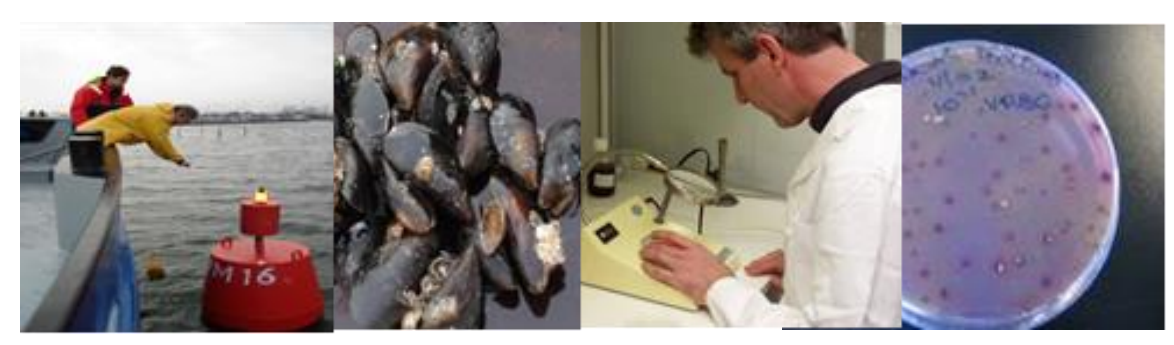

Auteur(s): $\quad$ M. Kotterman, A.C.M van Gool \& M. Poelman

Publicatiedatum: 31 oktober 2017 
Schelpdierwateronderzoek 2016. Wageningen Marine Research Wageningen UR (University \& Research Centre), Wageningen Marine Research rapport C072/17. 34 blz.

Keywords: contaminanten, schelpdieren, zware metalen, Rijkswaterstaat, microbiologie.

Opdrachtgever: Rijkswaterstaat

T.a.v.: Mervyn Roos

Postbus 17

8200 AA Lelystad

Dit rapport is gratis te downloaden van: https://doi.org/10.18174/423686

Wageningen Marine Research verstrekt geen gedrukte exemplaren van rapporten.

Wageningen Marine Research Wageningen UR is ISO 9001:2008 gecertificeerd.

Foto omslag: WMR collectie

(C) 2017 Wageningen Marine Research Wageningen UR

Wageningen Marine Research, onderdeel van Stichting Wageningen Research KvK nr. 09098104,

IMARES BTW nr. NL 8113.83.696.B16

Code BIC/SWIFT address: RABONL2U

IBAN code: NL 73 RABO 0373599285
De Directie van Wageningen Marine Research is niet aansprakelijk voor gevolgschade, noch voor schade welke voortvloeit uit toepassingen van de resultaten van werkzaamheden of andere gegevens verkregen van Wageningen Marine Research opdrachtgever vrijwaart Wageningen Marine Research van aanspraken van derden in verband met deze toepassing.

Dit rapport is vervaardigd op verzoek van de opdrachtgever hierboven aangegeven en is zijn eigendom. Niets uit dit rapport mag weergegeven en/of gepubliceerd worden, gefotokopieerd of op enige andere manier gebruikt worden zonder schriftelijke toestemming van de opdrachtgever. 


\section{Inhoud}

$1 \quad$ Inleiding

1.1 Schelpdierwater

1.2 Doel van het onderzoek

2

$\begin{array}{ll}\text { Methoden } & 6\end{array}$

$\begin{array}{lll}2.1 & \text { Bemonsteringslocaties en monstername } & 6\end{array}$

$\begin{array}{lll}2.2 & \text { Analyses } & 7\end{array}$

$\begin{array}{llr}2.3 & \text { Monsternamen } & 8\end{array}$

$\begin{array}{llr}2.4 & \text { Veldmetingen en zintuiglijke waarnemingen } & 9\end{array}$

$\begin{array}{ll}2.5 & \text { Microbiologische analyses } \\ 2.6 & 10\end{array}$

$\begin{array}{ll}2.6 & \text { Chemische analyses } \\ \end{array}$

2.6.1 Monstervoorbereiding 11

2.6.2 Analysemethoden van stofgroepen 11

2.6.3 Data opslag en kwaliteitsborging contaminanten $\quad 13$

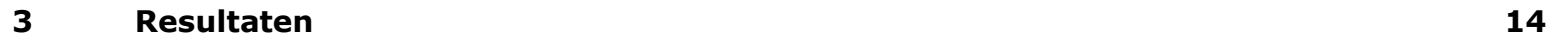

3.1 Microbiologische analyses, zintuiglijke warnemingen en veldmetingen. 14

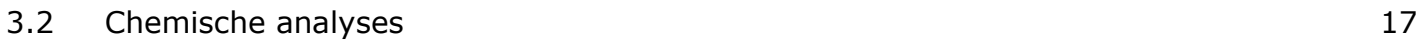

4 Conclusies en aanbevelingen $\quad 22$

$\begin{array}{lr}\text { Literatuur } & 23\end{array}$

$\begin{array}{lr}\text { Verantwoording } & 25\end{array}$

$\begin{array}{llll}\text { Bijlage } 1 \text { Monsterlocaties Zuidelijk Westelijke Delta } & 26\end{array}$

$\begin{array}{llr}\text { Bijlage } 2 & \text { Monsterlocaties Waddenzee } & \mathbf{2 7}\end{array}$

$\begin{array}{lll}\text { Bijlage } 3 & \text { Gehalten aan spoorelementen in schelpdieren } 2016 & 28\end{array}$

Bijlage $4 \quad$ PCB's en HCB gehalten in schelpdieren $2016 \quad 30$

$\begin{array}{lll}\text { Bijlage } 5 & \text { Resultaten referentiematerialen } & 31\end{array}$

Bijlage $6 \quad$ Resultaten Ringonderzoek Quasimeme in biota 32

$\begin{array}{lll}\text { Bijlage } 7 & \text { Rapportagegrenzen en meetonzekerheid } & 33\end{array}$ 


\section{Samenvatting}

In november en december 2016 is voor Rijkswaterstaat onderzoek verricht naar de schelpdierwaterkwaliteit in de Nederlandse kustwatergebieden. Doel hiervan is het vaststellen van de gehalten aan microbiologische verontreinigingen (fecale coliformen en Escherischia coli) en contaminanten (zware metalen en gehalogeneerde organische stoffen) in schelpdiervlees. Daarnaast zijn zintuiglijke waarnemingen op het schelpdiervlees en veldmetingen voor de verschillende fysische parameters in het oppervlaktewater uitgevoerd. De monitoringdata zijn getoetst aan de eisen gesteld in de richtlijn schelpdierwaterkwaliteit (2006/113/EC). Op grond van de Kaderrichtlijn Water (2000/60/EG) (KRW) artikel 22 is de Schelpdierwaterrichtlijn in 2013 vervallen, onder voorwaarde dat het door deze richtlijnen geboden beschermingsniveau wordt gehandhaafd. De monitoring heeft plaatsgevonden op 12 locaties in gebieden waar schelpdierproductie/visserij voorkomt of mogelijk plaats kan vinden, namelijk de Westerschelde, Grevelingen, Oosterschelde, Voordelta en de Waddenzee.

Op alle onderzochte locaties zijn de geconstateerde mediaan- en individuele waarden voor fecale coliformgehalten lager dan de norm van 300 fecale coliformen per $100 \mathrm{ml}$ schelpdiervlees en -vocht. Hetzelfde beeld wordt gezien voor Escherischia coli (E. coli) gehalten. Alle waarden zitten ruim onder de bijhorende norm van 230 E. coli per 100 gram schelpdiervlees en -vocht. Met de resultaten wordt voldaan aan het Nederlandse besluit kwaliteitsdoelstellingen en metingen oppervlaktewateren conform de richtlijn schelpdierwater.

Tijdens de zintuigelijke waarnemingen was geen zichtbare olie op of aan het oppervlakte water aanwezig. De subjectieve waarneming op geur en smaak van de gemonsterde schelpdieren vertoonde geen bijzonderheden.

Op basis van de monitoring kan worden gesteld dat de schelpdierwaterkwaliteit in december 2016 op alle bemonsterde locaties en voor alle gemeten stoffen voldeed aan de gestelde criteria in de richtlijn. 


\subsection{Schelpdierwater}

Schelpdierwateren moeten voldoen aan kwaliteitsnormen. De Europese lidstaten zijn verplicht regelmatig monsters te nemen om eventuele verontreinigingen vast te stellen en programma's tot vermindering van de verontreiniging op te stellen.

De Centrale Informatievoorziening Rijkswaterstaat (voorheen Waterdienst) geeft onder andere uitvoering aan één van deze richtlijnen, de schelpdierwaterrichtlijn (2006/113/EC, gecodificeerde versie van 79/923/EC). Deze taak bestaat uit het aanwijzen, beschermen en ondersteunen van verbeteringen van de kwaliteit van de schelpdierwateren. Op grond van de Kaderrichtlijn Water (2000/60/EG) (KRW) artikel 22 is de Schelpdierwaterrichtlijn in 2013 vervallen, onder voorwaarde dat het door deze richtlijnen geboden beschermingsniveau wordt gehandhaafd.

De scheldierwater richtlijn heeft als doel een goede kwaliteit van schelpdierwater in de EU te bereiken, In het kader van het Besluit kwaliteitsdoelstellingen en monitoring water (BKMW) zijn deze eisen vastgelegd (conform de schelpdierwaterichtlijn). Het BKMW vormt de nationale implementatie van de kwaliteitsdoelstellingen van de Europese kaderrichtlijn water (KRW). Naast deze richtlijn zijn nog enkele andere richtlijnen aanwezig, welke voorzien in specifieke hygiëne en productie-eisen voor tweekleppige weekdieren (General Food Law, 852/2004/EC, 853/2004/EC en 854/2004/EC). Deze vallen buiten het bestek van de Schelpdierwaterrichtlijn en daarmee buiten de scope van het uitgevoerde onderzoek.

Centrale Informatievoorziening Rijkswaterstaat heeft Wageningen Marine Research verzocht de monitoring van de schelpdierwateren op 12 locaties in de Nederlandse kustwateren uit te voeren. De voorwaarden voor deze monitoring zijn opgenomen in het projectplan "Monitoring schelpdierwater; projectplan chemisch meetnet MWTL 2013" (24 oktober 2013). Voorliggend rapport geeft een omschrijving van de werkzaamheden en de resultaten van de monitoring.

De monitoring vindt in november/december plaats op 12 locaties in gebieden waar schelpdierproductie/visserij voorkomt, namelijk de Westerschelde, Grevelingenmeer, Oosterschelde, Voordelta en de Waddenzee. De bemonsteringsfrequentie van het schelpdieronderzoek is vanaf 2013 eenmaal per 3 jaar.

\subsection{Doel van het onderzoek}

Doel van het onderzoek was het nemen van schelpdiermonsters en een aantal voorgeschreven analyses uitvoeren om zodoende te kunnen vaststellen of op de diverse schelpdierwaterlocaties wordt voldaan aan de criteria zoals gesteld in de schelpdierwaterrichtlijn.

Onderdeel van de analyses zijn

- het vaststellen van de gehalten aan fecale coliformen (thermotolerante fecale colibacteriën) en E. coli (volgens MPN ISO/TS 16649-3.),

- bepalen van gehaltes aan zware metalen en gehalogeneerde organische stoffen in schelpdiervlees.

- Doen van zintuigelijke waarnemingen op het schelpdiervlees.

- Doen van veldmetingen voor de verschillende parameters in het oppervlaktewater (zuurgraad, temperatuur, zuurstof, saliniteit, gesuspendeerde stoffen, kleurintensiteit, windsnelheid, olie (op het water) en smaak (schelpdieren). 


\section{$2 \quad$ Methoden}

Het schelpdierwateronderzoek 2016 bestaat uit bemonsteren van schelpdieren en het bepalen van microbiologische en chemische analyses in de Nederlandse schelpdierproductiewateren.

\subsection{Bemonsteringslocaties en monstername}

De locaties die bemonsterd zijn, zijn genoemd in Tabel 1. In bijlage 1 en 2 staan de locaties van de Zuidelijke Delta en de Waddenzee grafisch weergegeven.

De coördinatie van de bemonstering van deze locaties is verzorgd door de opdrachtnemer (Wageningen Marine Research).

Tabel 1. Bemonsteringslocaties en organismen met de daaraan toebehorende DONAR code zoals aangegeven in het Projectplan Monitoring schelpdierwater (24 oktober 2013).

\begin{tabular}{|c|c|c|c|}
\hline Gebied, locatie & DONAR code & $\begin{array}{l}\text { Bemonsterd } \\
\text { organisme }\end{array}$ & $\begin{array}{l}\text { Uitgehangen } \\
\text { organisme }\end{array}$ \\
\hline $\begin{array}{l}\text { Oosterschelde, Nunnenplaatje } \\
\text { zuidwest (Hammen 55) }\end{array}$ & NUNNPJZWT & Mossel & \\
\hline $\begin{array}{l}\text { Oosterschelde, Burghsluis tussen } \\
\text { Westbout en Burghsluis (Hammen 10) }\end{array}$ & BURGHSWBBSS & Mossel & \\
\hline $\begin{array}{l}\text { Oosterschelde, Yerseke, } \\
\text { verwaterplaats } \\
\text { (Bank } 316 \text { e.o.) }\end{array}$ & YERSKVWTPS & Mossel & \\
\hline Westerschelde, Hooge platen & HOOGPTN & Mossel & Mossel* \\
\hline $\begin{array}{l}\text { Westerschelde, Hoedekenskerke, boei } \\
4\end{array}$ & HOEDKKKBI4 & Mossel & Mossel* \\
\hline $\begin{array}{l}\text { Voordelta, Kop van Goeree nabij } \\
\text { Slijkgat, boei P4 }\end{array}$ & SLIJKGBISG18 & Mossel & \\
\hline Voordelta, Domburg Badstrand & DOMBBSD & Mossel & \\
\hline Grevelingen, Stampersplaat noord & STAMPPND & $\begin{array}{c}\text { Oester (chemisch) } \\
\text { Mossel } \\
\text { (microbiologie)* }^{*}\end{array}$ & Mossel* \\
\hline $\begin{array}{l}\text { Waddenzee West, } \\
\text { Westkom/Scheurrak }\end{array}$ & WESTKSRK & Mossel & \\
\hline Waddenzee West, Doove Balg midden & DOOVBMDN & Mossel & \\
\hline $\begin{array}{l}\text { Waddenzee Oost, Zoutkamperlaag, } \\
\text { Oort }\end{array}$ & OORT & Mossel & \\
\hline Waddenzee Oost, Dantziggat & DANTZGT & Mossel & \\
\hline
\end{tabular}

*Analyses ten behoeve van microbiologisch onderzoek worden verricht in mosselen. Deze dienen als indicatororganisme voor de temporele microbiële status van de kustwateren. Om geen trendbreuk te krijgen met voorgaande jaren zijn in 2016 in de Grevelingen de microbiologische analyses ook uitgevoerd in mosselmatrix. Aangezien op de bemonsteringslocatie geen mosselen voorkomen zijn mosselen uitgehangen. In de Westerschelde kunnen wel voldoende mosselen worden verzameld voor chemische analyse, maar voor de microbiologische analyse worden extra mosselen uitgehangen. 
Voor de analyse op zware metalen en gehalogeneerde organische stoffen zijn mengmonsters van mosselen of oesters genomen die van nature aanwezig zijn op de locatie. Op de volgende locaties zijn mosselen (Mytilus edulis) bemonsterd (zie Tabel 1): Hooge Platen t.h.v. een kalibratiepaal en Hoedekenskerke t.h.v. een golfbreker op het vaste wal (beide Westerschelde), Burghsluis tussen Westbout en Burgsluis, Nunnenplaatje zuidwest en Yerseke verwaterplaats (alle drie in het gebied Oosterschelde); Kustzone Slijkgat boei P 4 en Kustzone Domburg badstrand in de Voordelta; Westkom/Scheurrak/ (gekozen voor het nabij gelegen Vlieter i.v.m. de juiste maat mossel) en Doove Balg midden (alle twee in het gebied Waddenzee West); Oort (zuidrand Brakzand) en Dantziggat (beiden in het gebied Waddenzee Oost). Japanse oesters (Crassostrea gigas) zijn bemonsterd op locatie Stampersplaat Noord in het gebied Grevelingen. Op deze bemonsteringslocatie (of in de nabijheid hiervan) zijn onvoldoende mosselen te vinden of de kwaliteit (specifiek consumptie formaat) is onvoldoende voor microbiologisch onderzoek. Daarom is besloten om als matrix voor de chemische analyses over te gaan op oesters. Hiermee kunnen gegevens worden verzameld voor een schelpdier dat tevens doelsoort voor de schelpdierwaterrichtlijn is. Oesters en mosselen hebben verschillende accumulatiekarakteristieken voor o.a. zware metalen.

\subsection{Analyses}

Voor wat betreft de microbiologische analyses zijn het schelpdiervlees en -vocht in de schelp van mosselen geanalyseerd op thermotolerante fecale colibacteriën (fecale coliformen) en op E. coli. Per locatie zijn vijf deelmonsters genomen, waarin de hoeveelheid thermotolerante coli bacteriën per 100 $\mathrm{ml}$ schelpdiervlees en -vocht en de E. coli per 100 gram zijn bepaald. Dit wordt in DONAR gerapporteerd als aantal per liter en aantal per $\mathrm{kg}$ met resp. de EHD /l en / kg. De verschillende rapportage-eenheden zijn een gevolg van de gekozen methoden.

De individuele resultaten en de mediaanwaarde zijn gerapporteerd.

Voor de chemische analyses is van 5 deelmonsters per locatie een samengesteld monster (mengmonster) geanalyseerd. De analyse bestaat uit:

$\begin{array}{lll}\text { Zware metalen } & \text { DONAR-code } & \text { CAS-RN } \\ \text { Arseen } & \mathrm{As} & 7440-38-2 \\ \text { Cadmium } & \mathrm{Cd} & 7440-43-9 \\ \text { Chroom } & \mathrm{Cr} & 7440-47-3 \\ \text { Koper } & \mathrm{Cu} & 7440-50-8 \\ \text { Kwik } & \mathrm{Hg} & 7439-97-6 \\ \text { Lood } & \mathrm{Pb} & 7439-92-1 \\ \text { Nikkel } & \mathrm{Ni} & 7440-02-0 \\ \text { Zink } & \mathrm{Zn} & 7440-66-6\end{array}$

$\begin{array}{lll}\text { Gehalogeneerde organische stoffen } & \begin{array}{l}\text { DONAR- } \\ \text { code }\end{array} & \text { CAS-RN } \\ \text { HCB } & \text { HCB } & 118-74-1 \\ \text { PCB138 } & \text { PCB138 } & 35065-28-2 \\ \text { PCB153 } & \text { PCB153 } & 35065-27-1 \\ & & \\ \text { Fysiologisch } & & \\ \text { As } & \% \text { GV } & \\ \text { Droge stof } & \% \text { DS } & \\ \text { Vet, totaal (Bligh \& Dyer) } & \text { VET } & \end{array}$


Op het moment van monstername vinden zintuigelijke waarnemingen plaats op aanwezigheid van olie op of aan het wateroppervlak en aan het schelpdiervlees. Deze laatste waarnemingen (geur en smaak) zijn op basis van een inschatting van de monsternemer uitgevoerd (expert beoordeling) en zijn daarmee subjectief van aard. In geval van onverwachte afwijkingen in de waarnemingen wordt contact opgenomen met de opdrachtgever.

\subsection{Monsternamen}

De monsternamen zijn, waar mogelijk, uitgevoerd door een medewerker van Wageningen Marine Research met assistentie van de Rijksvaartuigen "Phoca", "Regulus", "Luctor" en de "Krukel" van de Rijksrederij. Er is gebruik gemaakt van interne Wageningen Marine Research voorschriften voor het uitvoeren van de veldwerkzaamheden (2.16.2.27 Protocol voor het uitvoeren van veldwerkzaamheden t.b.v. de Schelpdierwaterkwaliteit in Nederlandse kustwatergebieden in 2016). De bemonsteringsfrequentie van het schelpdieronderzoek is vanaf 2013 eenmaal per 3 jaar, in de maanden november/december.

De monsternamen bestemd voor microbiologische analyses zijn gericht op het nemen van vijf deelmonsters schelpdieren per locatie, indien aanwezig. Wanneer onvoldoende schelpdieren voorradig waren op de monsterlocatie, is overgegaan op het uithangen van mosselen (Mytilus edulis). Deze mosselen zijn afkomstig uit een klasse A productiegebied (Yerseke Bank) (conform richtlijn $854 / 2004 / E C)$, waarbij uit monitoring gegevens over het jaar geen normoverschrijding voor $E$. coli is geconstateerd. Van het uitgangsmateriaal is een referentiemonster geanalyseerd om de $E$. coli waarden te verifiëren. Op het meetpunt zijn dan voor een accumulatieduur van minimaal 4 uur mosselen in korven uitgehangen (conform Hulsman, 1994). Locaties waar in 2016 mosselen zijn uitgehangen zijn Westerschelde nabij Hooge Platen, Westerschelde t.h.v. Hoedekenskerke en de Grevelingen. Alle deelmonsters voor microbiologische analyses zijn maximaal 48 uur bewaard bij 4-7 ${ }^{\circ} \mathrm{C}$ tot verdere analyse (Anoniem, 2010).

Voor het bepalen van de gesuspendeerde stoffen is een 1 liter fles met oppervlaktewater tot aan de rand gevuld op betreffende locatie $(10-40 \mathrm{~cm}$ onder het oppervlak). De flessen zijn opgeslagen bij 4-7 ${ }^{\circ} \mathrm{C}$.

De mengmonsters voor analyse op zware metalen en gehalogeneerde organische stoffen zijn ingevroren en opgeslagen bij ca. $-20{ }^{\circ} \mathrm{C}$. Deze monsters zijn bevroren (ca. $-20^{\circ} \mathrm{C}$ ) getransporteerd via JBM Koeriers en overgebracht naar het laboratorium van Wageningen Marine Research in IJmuiden voor analyse. 


\subsection{Veldmetingen en zintuiglijke waarnemingen}

Tijdens de monsternamen zijn de zuurgraad $(\mathrm{pH})$, zuurstof (absoluut in $\mathrm{mg} / \mathrm{I}$ en verzadigingswaarde in $\%)$, temperatuur $\left({ }^{\circ} \mathrm{C}\right)$, en saliniteit (dimensieloos) gemeten conform 'Standard methods for examination of water \& wastewater van APHA (APHA, 2005)'.

Hierbij is gebruik gemaakt van gekalibreerde portable meters en Intellical elektroden van roestvast staal van HACH LANGE (Tabel 2).

Tabel 2. Apparatuur en karakteristieken voor veldmeldingen

\begin{tabular}{|l|l|l|l|l|}
\hline & $\begin{array}{l}\text { HACH LANGE } \\
\text { Portable meter }\end{array}$ & Electrode (type) & Nauwkeurigheid & Resolutie \\
\hline Zuurgraad & HQ 40d & $\begin{array}{l}\text { pHc101 } \\
\text { SN072422560-0001 }\end{array}$ & $0.001^{*}$ & 0.01 \\
\hline Zuurstof & HQ 40d & $\begin{array}{l}\text { LDO (Luminescent } \\
\text { Dissolved Oxygen) }\end{array}$ & $\pm 1 \%$ & $\begin{array}{l}0.01 \mathrm{mg} / \mathrm{l} \text { of } \\
0.1 \% \text { verzadiging }\end{array}$ \\
\hline Saliniteit & $\begin{array}{l}\text { HQ14d } \\
\text { Conductivity }\end{array}$ & $\begin{array}{l}\text { CDC 401 } \\
\text { SN080282580009 }\end{array}$ & $\pm 0,1$ & 0.01 \\
\hline Temperatuur & HQ 40d & Geïntegreerd & $\pm 0.3^{\circ} \mathrm{C}$ & $0.1^{\circ} \mathrm{C}$. \\
\hline
\end{tabular}

*Conform specificatie leverancier

De kleurintensiteit van het oppervlaktewater is bepaald met een $\mathrm{HACH}$ Color testkit, model $\mathrm{CO}-1$ (Cat. no. 2234-00), waarbij een buis gevuld met $15 \mathrm{ml}$ leidingwater wordt vergeleken met een oppervlaktewater-monster tegen de achtergrond van een PT/Co kleurenschaal. Hierna wordt de uitlezing uitgevoerd op een schaal tussen 0 en 100 eenheden (werkprotocol Wageningen Marine Research 2.16.2.22).

Aan boord van het schip zijn 5 tot 10 schelpdieren ( mosselen of oesters die van nature aanwezig zijn op de locatie) geopend en er op geur en smaak beoordeeld.

Er is visueel geïnspecteerd op aanwezigheid van zichtbare olie op of aan de wateroppervlakte van het te bemonsteren gebied.

Om de hoeveelheid gesuspendeerde stoffen te bepalen is een liter water bemonsterd en direct in de koelkast geplaatst voor latere analyse. Een liter water is m.b.v. een filtreeropstelling over een reeds gewogen filter (Whatman GF/C poriegrootte $2 \mu \mathrm{m}$ ) gebracht waarna het 24 uur is gedroogd in een droogstoof bij $70{ }^{\circ} \mathrm{C}$. De hoeveelheid gesuspendeerde stof is uitgedrukt in het aantal mg per liter oppervlakte water. $\mathrm{Er}$ is gewerkt volgens een intern werkprotocol (Wageningen Marine Research werkprotocol 2.16.2.04). 


\subsection{Microbiologische analyses}

Voor de bepaling van het aantal fecale coliformen in het schelpdiervlees en -vocht is gebruik gemaakt van de MacConkey telplaatmethode (NF V08-060 aangepast). Deze analyses zijn uitbesteed aan het geaccrediteerde laboratorium SGS Belgium NV.

Van de mosselen is per monster 20 gram schelpdiervlees en -vocht gebruikt voor de telplaatmethode, waarbij een decimale verdunning van het monster heeft plaatsgevonden en waarna deze in vijfvoud op vaste selectieve voedingsbodems (MacConkey-agar) is gebracht. Hierna is een afdeklaag aangebracht met vloeibaar MacConkey-agar.

$\mathrm{Na}$ incubatie $\left(20-24\right.$ uur $44^{\circ} \mathrm{C}$ ) heeft directe telling van de specifieke kolonies plaatsgevonden (donkerrode kolonies omgeven door een precipitatie van neergeslagen galzouten).

Wanneer aanwezigheid van specifieke kolonies is vastgesteld is een bevestigingsreactie met briljantgroen-gal-lactose-bouillon uitgevoerd om kwalitatief aan te tonen of fecale coliformen aanwezig zijn.

Volgens de Europese verordening, betreffende de vereiste kwaliteit van schelpdierwater $(2006 / 113 / E C)$ is een gehalte minder dan 300 fecale coliformen per $100 \mathrm{ml}$ schelpdiervlees en -vocht toelaatbaar.

De MacConkey telplaatmethode is gevalideerd aan de methode ISO 17521 (MPN) voor E. coli. Deze studie heeft uitgewezen dat beide methoden niet significant verschillend zijn (Mooijman, 2007). De validatiestudie heeft ook uitgewezen dat deze methoden voor fecale coliformen niet significant verschillend zijn (niet gerapporteerd). De methode die momenteel voor de bepaling van $E$. coli in schelpdierproductiegebieden wordt voorgeschreven (ISO 16649-3) (anoniem, 2005) is significant verschillend aan de MacConkey methode voor E. coli, er is geen vergelijking gemaakt voor fecale coliformen. Voor ISO 17521 en ISO 16649-3 geldt dat deze significant niet verschillend zijn.

$\mathrm{Er}$ is tot dusverre geen validatie studie uitgevoerd tussen de huidig toegepaste MacConkey telplaat methode en de voorgeschreven NEN6572 (ingetrokken standaard) methode (en/of Richtlijn 2006/113, bijlage 1). De MacConkey methode wordt sinds de implementatie van het programma (voor 1994) gebruikt voor de bepaling van de aantallen fecale coliformen per $100 \mathrm{ml}$ schelpdiervlees. De gerapporteerde waarden conform de telplaatmethoden zijn weergegeven in f.c. $/ 100 \mathrm{ml}$.

Aanvullend is voor de $E$. coli bepaling een geaccrediteerde methode gehanteerd volgens ISO/TS 16649-3. Deze waarden worden eveneens gerapporteerd.

Deze analyse-instructie verschaft algemene richtlijnen voor het tellen van $\beta$-glucoronidase-positieve $E$. coli in producten bestemd voor menselijke consumptie of diervoeding door berekening van de "Most Probable Number" (MPN) na incubatie bij $37^{\circ} \mathrm{C}$ en vervolgens bij $44^{\circ} \mathrm{C}$. Ze is conform aan de ISO methode (International Standardisation Organisation - ISO/TS 16649-3). De waarden worden gerapporteerd in MPN / 100 gram. 


\subsection{Chemische analyses}

\subsubsection{Monstervoorbereiding}

Schelpdiermonsters van de 12 verschillende locaties zijn op 13 december 2016 door Wageningen Marine Research Yerseke ingevroren afgeleverd bij Wageningen Marine Research in IJmuiden ten behoeve van chemische analyses in het schelpdiervlees.

$\mathrm{Na}$ ontdooien en uitlekken van de monsters is het schelpdiervlees verzameld m.b.v. titaanmessen en gehomogeniseerd met behulp van een Ultra Turrax. Genoemde werkzaamheden zijn uitgevoerd in een contaminatie arme ruimte. Voor elke locatie is een mengmonster gemaakt van tenminste 75 exemplaren. Voor de monsters kleine mosselen $(<4 \mathrm{~cm})$, afkomstig van de DONAR-locaties NUNNPJZWT, HOOGPTN, HOEDKKKBI4 en DOMBBSD, is tenminste 100 gram mosselvlees verzameld. Dit om de gewenste hoeveelheid schelpdiervlees- en vocht te verkrijgen.

In de 12 mengmonsters zijn chemische analyses uitgevoerd.

\subsubsection{Analysemethoden van stofgroepen}

De te bepalen stofgroepen zijn volgens de volgende methoden geanalyseerd.

\section{OCP's en PCB's:}

De stofgroepen PCB's en OCP worden in plaats van de traditionele methode bepaald door een vernieuwde methode. De traditionele methode bestaat uit soxhlet extractie, gevolgd door een vetverwijderingstap met behulp van een tweevoudige kolom chromatografische scheiding, waarna de analyse plaatsvindt met behulp van GC-ECD. Bij de vernieuwde methode worden de monsters opgewerkt door middel van een ASE-extractie. De halogeenverbindingen worden door middel van inline vetverwijdering m.b.v. florisil geïsoleerd, waarna analyse plaatsvindt met behulp van gaschromatografie. De monsters worden gemeten tegen een kalibratiecurve en gedetecteerd met GCMS.

De methode is vastgelegd in Wageningen Marine Research Interne Standaard Werkwijze (ISW) ISW 2.10.3.050 "Dierlijk weefsel. Bepalen van het gehalte aan polychloorbifenylen (PCB) na ASEextractie;(GC-MS) en "Dierlijk weefsel. Bepalen van het gehalte aan organochloorbestrijdingsmiddelen (OCP) na ASE-extractie; GC-MS" en staat op de scope van de Raad voor Accreditatie onder testlaboratoriumnummer L097, verrichting nummer 20 voor zowel de PCB als OCP.

\section{Metalen:}

Een deel van het monster wordt in duplo ontsloten met salpeterzuur en waterstofperoxide, volgens TNO Triskelion voorschrift TRIS/LSP/108. In de verkregen oplossing wordt het gehalte aan cadmium, koper, lood en zink bepaald m.b.v. ICP-MS, volgens voorschrift TRIS/LSP/055 en TRIS/LSP/108. De kwantificering vindt plaats aan de hand van externe kalibratiestandaarden en om te corrigeren voor fluctuaties in de apparatuur wordt gebruik gemaakt van een interne standaard (rhodium).

TNO Triskelion is geaccrediteerd door de Raad voor Accreditatie voor genoemde metalen (testlaboratoriumnummer L546, verrichting nummer 30). 


\section{Kwik:}

Voor de bepaling wordt het monster gedroogd en verast in een oven om kwik vrij te maken uit het monster. De vrijgekomen verbindingen worden d.m.v. zuurstof naar een catalyst tube geleid, waar oxidatie plaatsvindt en halogenen en stikstof- en zwaveloxiden worden verwijderd. De overige ontledingsproducten worden d.m.v. zuurstof naar een amalgamator geleid, waar de kwikverbindingen worden omgezet in metallisch kwik. Het gehalte aan kwik wordt vervolgens d.m.v. vlamloze atoomabsorptie spectrometrie bepaald. De monsters worden gemeten tegen een kalibratiecurve, die gemaakt is door het meten van verschillende hoeveelheden van een gecertificeerd referentiemateriaal. De methode is vastgelegd in Wageningen Marine Research ISW 2.10.3.025 "Dierlijk weefsel. Bepalen van het gehalte aan kwik m.b.v. SMS100 mercury analyser; vlamloze AAS" en staat op de scope van de Raad voor Accreditatie onder testlaboratoriumnummer L097, verrichting nummer 6.

\section{Vet:}

De totaal vet bepaling geschiedt volgens een aangepaste versie van de Bligh en Dyer methode, gebaseerd op een koude chloroform-methanol extractie.

De methode is vastgelegd in Wageningen Marine Research ISW 2.10.3.002 "Dierlijk weefsel. Bepalen van het gehalte aan vet volgens Bligh and Dyer; gravimetrie" en staat op de scope van de Raad voor Accreditatie onder testlaboratoriumnummer L097, verrichting nummer 1.

De bepaling van vrij extraheerbaar vet wordt uitgevoerd als onderdeel van de PCB analyse. Na de Soxhlet extractie wordt een deel van het extract drooggedampt en het residu gewogen. De bepaling van vrij extraheerbaar vet staat niet op de scope van de Raad voor Accreditatie.

\section{Droge stof en as:}

Voor de bepaling van het droge stofgehalte wordt het gewogen monster gemengd met een oppervlakte vergrotende stof, vervolgens gedroogd in een stoof ( $105^{\circ} \mathrm{C}, 3$ uur) en na afkoelen in een exsiccator teruggewogen.

De methode is vastgelegd in Wageningen Marine Research ISW 2.10.3.011 "Dierlijk weefsel. Bepalen van het gehalte aan vocht; gravimetrie" staat op de scope van de Raad voor Accreditatie onder testlaboratoriumnummer L097, verrichting nummer 2.

Voor de asbepaling wordt het monster langzaam verwarmd en gedroogd in een kroes op een kookplaat. Daarna wordt het monster gedurende 22 uur verast in een moffeloven bij een temperatuur van $550 \pm 15^{\circ} \mathrm{C}$. Na afkoelen in een exsiccator wordt het monster teruggewogen.

De methode is vastgelegd in Wageningen Marine Research ISW 2.10.3.018 "Dierlijk weefsel. Bepalen van het gehalte aan as; gravimetrie" en staat op de scope van de Raad voor Accreditatie onder testlaboratoriumnummer L097, verrichting nummer 4.

Het percentage asvrijdrooggewicht wordt berekend uit het gehalte droge stof en as. 


\subsubsection{Data opslag en -registratie}

De gegenereerde data worden opgeslagen in LIMS. Een DONAR-script is beschikbaar dat ervoor zorgt dat de gegevens uit LIMS op de juiste manier in een DONAR-file terecht komen. De analyseresultaten uit het meetrapport die in LIMS worden geïmporteerd, worden gecontroleerd door een andere analist die bevoegd is voor de uitvoering van betreffende bepaling dan de uitvoerend analist. De Exceltabellen die uit LIMS worden gegenereerd en in het rapport worden opgenomen, worden door de uitvoerende analisten gecontroleerd op eventuele fouten en geparafeerd voor vrijgave. Van elk analyseresultaat wordt beoordeeld of het voldoet aan de kwaliteitscriteria die worden genoemd in het betreffende ISW, indien dit niet het geval is wordt de reden daarvan in het rapport vermeld. 


\subsection{Microbiologische analyses, zintuiglijke waarnemingen en veldmetingen.}

De resultaten van het onderzoek zijn per locatie vermeld in Tabel 3a, Tabel 3b en Tabel 4. Naast de microbiologische resultaten in tabel $3 a$ en $3 b$ zijn tevens de data, tijdstippen, watertemperatuur en windsnelheden tijdens de monsternamen weergegeven. In tabel 4 zijn opgenomen de zintuiglijke waarnemingen (zichtbare olie op of aan het oppervlaktewater en geur/smaak van het schelpdiervlees) en veldmetingen.

Tabel 3a. Fecale coliformen in mosselen; Schelpdierwateronderzoek 2016 (November/December). De fecale coliform (f.c.) gehalten zijn uitgedrukt in het totaal aantal fecale coliformen per $100 \mathrm{ml}$ schelpdiervlees en -vocht.

\begin{tabular}{|c|c|c|c|c|c|c|c|c|c|c|}
\hline \multirow{2}{*}{$\begin{array}{l}\text { DONAR locatie } \\
\text { Toetsingsnorm } \\
\text { Fecale } \\
\text { coliformen* } \\
\end{array}$} & \multirow[t]{2}{*}{$\begin{array}{c}\text { Monster- } \\
\text { datum }\end{array}$} & \multirow[t]{2}{*}{ Tijd } & \multirow{2}{*}{$\begin{array}{c}\text { Wind- } \\
\text { snelheid } \\
(\mathrm{m} / \mathrm{s})\end{array}$} & \multirow[t]{2}{*}{$\begin{array}{c}\text { Temperatuur } \\
\left({ }^{\circ} \mathrm{C}\right)\end{array}$} & \multicolumn{6}{|c|}{$\begin{array}{c}\text { Fecale coliformen } \\
\text { (f.c./ } 100 \mathrm{ml})\end{array}$} \\
\hline & & & & & & & & & & $<300$ \\
\hline & & & & & 1 & 2 & 3 & 4 & 5 & Mediaan \\
\hline STAMPPND & $2 / 11 / 2016$ & $13: 20$ & 9.4 & 11.6 & $<20$ & $<20$ & $<20$ & $<20$ & $<20$ & $<20$ \\
\hline BURGHSWBBSS & $16 / 11 / 2016$ & 09:30 & 9.4 & 9.7 & $<20$ & 40 & $<20$ & $<20$ & $<20$ & $<20$ \\
\hline NUNNPJZWT & $16 / 11 / 2016$ & $08: 30$ & 9.4 & 10.1 & $<20$ & $<20$ & $<20$ & $<20$ & $<20$ & $<20$ \\
\hline YERSKVWTPS & $30 / 11 / 2016$ & $14: 00$ & 6.7 & 4.7 & $<20$ & 280 & 240 & $<20$ & 120 & 120 \\
\hline DOMBBSD & $09 / 11 / 2016$ & $14: 30$ & 6.7 & 9.3 & $<20$ & $<20$ & $<20$ & $<20$ & $<20$ & $<20$ \\
\hline SLIJKGBISG18 & $23 / 11 / 2016$ & $11: 00$ & 2.5 & 8.6 & $<20$ & $<20$ & $<20$ & $<20$ & $<20$ & $<20$ \\
\hline DANTZGT & $29 / 11 / 2016$ & $14: 00$ & 9 & 6.1 & $<20$ & $<20$ & $<20$ & $<20$ & $<20$ & $<20$ \\
\hline OORT & $28 / 11 / 2016$ & $15: 00$ & 2.5 & 6.3 & $<20$ & $<20$ & $<20$ & $<20$ & $<20$ & $<20$ \\
\hline DOOVBMDN & $15 / 11 / 2016$ & $11: 00$ & 6.7 & 8.1 & $<20$ & $<20$ & $<20$ & $<20$ & $<20$ & $<20$ \\
\hline WESTKSRK & $15 / 11 / 2016$ & $10: 00$ & 6.7 & 8.6 & $<20$ & $<20$ & $<20$ & $<20$ & $<20$ & $<20$ \\
\hline HOEDKKKBI4 & $7 / 12 / 2016$ & $16: 00$ & 6.7 & 7.1 & 20 & $<20$ & $<20$ & 80 & $<20$ & $<20$ \\
\hline HOOGPTN & $7 / 12 / 2016$ & $14: 15$ & 6.7 & 7.6 & $<20$ & $<20$ & 80 & $<20$ & 40 & $<20$ \\
\hline
\end{tabular}

* Richtlijn 2006/113/EG van het Europees Parlement en de raad van 12 december 2006 inzake de vereiste kwaliteit van schelpdierwater. 
Tabel 3b. E. coli in mosselen; Schelpdierwateronderzoek 2016 (November/December). De E. coli gehalten zijn uitgedrukt in het totaal aantal E. coli per 100 gram schelpdiervlees en -vocht.

\begin{tabular}{|c|c|c|c|c|c|c|c|c|c|c|}
\hline DONAR locatie & $\begin{array}{l}\text { Monster- } \\
\text { datum }\end{array}$ & Tijd & $\begin{array}{l}\text { Wind- } \\
\text { snelheid }\end{array}$ & $\begin{array}{c}\text { Temperatuur } \\
\left({ }^{\circ} \mathrm{C}\right)\end{array}$ & & & IPN & $\begin{array}{l}\text { coli } \\
100\end{array}$ & am) & \\
\hline Toetsingsnorm & & & & $\begin{array}{l}\text { dT } \leq 2 \text { (ten } \\
\text { opzichte van } \\
\text { natuurlijke } \\
\text { waarden) }\end{array}$ & & & & & & $<230$ \\
\hline & & & & & 1 & 2 & 3 & 4 & 5 & Mediaan \\
\hline STAMPPND & $2 / 11 / 2016$ & $13: 20$ & 9.4 & 11.6 & $<20$ & $<20$ & $<20$ & $<20$ & $<20$ & $<20$ \\
\hline BURGHSWBBSS & $16 / 11 / 2016$ & 09:30 & 9.4 & 9.7 & $<20$ & $<20$ & $<20$ & $<20$ & $<20$ & $<20$ \\
\hline NUNNPJZWT & $16 / 11 / 2016$ & $08: 30$ & 9.4 & 10.1 & $<20$ & $<20$ & $<20$ & $<20$ & $<20$ & $<20$ \\
\hline YERSKVWTPS & $30 / 11 / 2016$ & $14: 00$ & 6.7 & 4.7 & $<20$ & $<20$ & $<20$ & $<20$ & $<20$ & $<20$ \\
\hline DOMBBSD & $09 / 11 / 2016$ & $14: 30$ & 6.7 & 9.3 & $<20$ & $<20$ & $<20$ & $<20$ & $<20$ & $<20$ \\
\hline SLIJKGBISG18 & $23 / 11 / 2016$ & $11: 00$ & 2.5 & 8.6 & $<20$ & $<20$ & $<20$ & $<20$ & $<20$ & $<20$ \\
\hline DANTZGT & $29 / 11 / 2016$ & $14: 00$ & 9 & 6.1 & $<20$ & $<20$ & $<20$ & $<20$ & $<20$ & $<20$ \\
\hline OORT & $28 / 11 / 2016$ & $15: 00$ & 2.5 & 6.3 & $<20$ & $<20$ & $<20$ & $<20$ & $<20$ & $<20$ \\
\hline DOOVBMDN & $15 / 11 / 2016$ & $11: 00$ & 6.7 & 8.1 & $<20$ & $<20$ & $<20$ & $<20$ & $<20$ & $<20$ \\
\hline WESTKSRK & $15 / 11 / 2016$ & $10: 00$ & 6.7 & 8.6 & $<20$ & $<20$ & $<20$ & $<20$ & $<20$ & $<20$ \\
\hline HOEDKKKBI4 & $7 / 12 / 2016$ & $16: 00$ & 6.7 & 7.1 & $<20$ & $<20$ & $<20$ & $<20$ & $<20$ & $<20$ \\
\hline HOOGPTN & $7 / 12 / 2016$ & $14: 15$ & 6.7 & 7.6 & $<20$ & $<20$ & $<20$ & $<20$ & $<20$ & $<20$ \\
\hline
\end{tabular}

* Richtlijn 854/2004/EG van het Europees Parlement en de raad van 12 december 2006 inzake de vereiste kwaliteit van schelpdierwater. 
Tabel 4. Veldmetingen en zintuiglijke waarnemingen (olie en geur/smaak van het schelpdiervlees)

Schelpdierwateronderzoek 2016

\begin{tabular}{|c|c|c|c|c|c|c|c|c|}
\hline DONAR locatie & $\mathrm{pH}$ & $\begin{array}{c}\text { Zuurstof } \\
(\mathrm{mg} / \mathrm{l})\end{array}$ & $\% \mathrm{O}_{2}$ & Saliniteit & $\begin{array}{c}\text { Kleurintensiteit } \\
\text { Pt/Co-schaal }\end{array}$ & $\begin{array}{l}\text { Gesuspen- } \\
\text { deerde } \\
\text { Stoffen } \\
(\mathrm{mg} / \mathrm{l})\end{array}$ & $\begin{array}{l}\text { Geur en } \\
\text { smaak } \\
\text { van het } \\
\text { schelp- } \\
\text { diervlees }\end{array}$ & $\begin{array}{c}\text { Olie } \\
\text { aanwezig } \\
\text { op of } \\
\text { aan } \\
\text { het } \\
\text { water }\end{array}$ \\
\hline Toetsingsnorm $^{1)}$ & $7-9$ & & $\geq 80$ & $\begin{array}{c}\text { Bindende } \\
\text { waarde } \\
<40 \\
\text { Streefwaarde } \\
12-38 \\
\end{array}$ & $\begin{array}{c}\text { Normering } \\
\text { alleen bij } \\
\text { lozing }^{2)}\end{array}$ & $\begin{array}{c}\text { Normering } \\
\text { alleen bij } \\
\text { lozing }^{3)}\end{array}$ & normaal & afwezig \\
\hline STAMPPND & 8.01 & 7.63 & 87.5 & 29.7 & 7.0 & 1.6 & normaal & afwezig \\
\hline BURGHSWBBSS & 8.20 & 8.66 & 97.5 & 31.5 & 8.0 & 19.8 & normaal & afwezig \\
\hline NUNNPJZWT & 8.11 & 8.73 & 98.0 & 30.8 & 10.0 & 14.8 & normaal & afwezig \\
\hline YERSKVWTPS & 8.02 & 9.08 & 95.3 & 29.3 & 13.0 & 8.4 & normaal & afwezig \\
\hline DOMBBSD & 8.28 & 8.39 & 90.7 & 31.6 & 12.0 & 43.9 & normaal & afwezig \\
\hline SLIJKGBISG18 & 8.08 & 8.72 & 96.9 & 15.2 & 10.0 & 11.9 & normaal & afwezig \\
\hline DANTZGT & 7.78 & 12.76 & 100.9 & 27.9 & 20.0 & 26.6 & normaal & afwezig \\
\hline OORT & 7.42 & 13.15 & 102.2 & 23.9 & 25.0 & 33.5 & normaal & afwezig \\
\hline DOOVBMDN & 8.20 & 10.24 & 87.9 & 24.6 & 0.0 & 10.1 & normaal & afwezig \\
\hline WESTKSRK & 8.19 & 10.86 & 92.5 & 21.94 & 2.0 & 9.7 & normaal & afwezig \\
\hline HOEDKKKBI4 & 7.94 & 9.15 & 95.2 & 20.2 & 15.0 & 22.8 & normaal & afwezig \\
\hline HOOGPTN & 8.01 & 9.04 & 94.5 & 25.2 & 8.0 & 38.4 & normaal & afwezig \\
\hline
\end{tabular}

1) Richtlijn 2006/113/EG van het Europees Parlement en de raad van 12 december 2006 inzake de vereiste kwaliteit van schelpdierwater.

2) De kleur van het water na filtering, veroorzaakt door een lozing, mag in het door deze lozing beïnvloede schelpdierwater niet meer dan $10 \mathrm{mg} \mathrm{Pt/l}$ afwijken van de kleur die is gemeten in de niet beïnvloede wateren.

3) De stijging van het gehalte aan gesuspendeerde stoffen die door een lozing wordt veroorzaakt, mag in het door deze lozing beïnvloede schelpdierwater niet meer bedragen dan $30 \%$ van het gehalte gemeten in niet-beïnvloed water 


\subsection{Chemische analyses}

De resultaten vermeld in dit rapport zijn alleen van toepassing op de geanalyseerde monsters.

De monsters zijn in januari 2017 geanalyseerd in het laboratorium locatie IJmuiden.

De resultaten van de analyses van de 12 monsters op productbasis ('natgewicht') zijn in de tabellen 5 , 6 en 7 weergegeven.

In de bijlagen 3 en 4 van dit rapport zijn omrekeningen weergegeven op respectievelijk droge stof, asvrijdrooggewicht basis en vet basis.

Tabel 5. Gehalten aan spoorelementen in mg/kg product (Kwik, Cadmium, Lood, Koper en Zink)

\begin{tabular}{|c|c|c|c|c|c|c|c|}
\hline LIMSnr. & DONAR code & Monstersoort & Kwik & Cadmium & Lood & Koper & Zink \\
\hline & & & $\mathrm{Q}$ & $\mathrm{Q}$ & $\mathrm{Q}$ & $\mathrm{Q}$ & $\mathrm{Q}$ \\
\hline $\mathbf{2 0 1 6 / 3 0 7 2}$ & BURGHSWBBSS & mosselen & 0.018 & 0.040 & 0.25 & 1.4 & 14 \\
\hline $\mathbf{2 0 1 6 / 3 0 7 5}$ & NUNNPJZWT & mosselen & 0.022 & 0.049 & 0.22 & 1.5 & 12 \\
\hline $\mathbf{2 0 1 6 / 3 0 7 8}$ & YERSKVWTPS & mosselen & 0.016 & 0.038 & 0.20 & 1.2 & 13 \\
\hline $\mathbf{2 0 1 6 / 3 0 8 1}$ & HOOGPTN & mosselen & 0.024 & 0.26 & 0.32 & 1.4 & 16 \\
\hline $\mathbf{2 0 1 6 / 3 0 8 4}$ & HOEDKKKBI4 & mosselen & 0.030 & 0.89 & 0.40 & 1.3 & 21 \\
\hline $\mathbf{2 0 1 6 / 3 0 8 7}$ & SLIJKGBISG18 & mosselen & 0.015 & 0.079 & 0.22 & 1.8 & 10 \\
\hline $\mathbf{2 0 1 6 / 3 0 9 0}$ & DOMBBSD & mosselen & 0.023 & 0.059 & 0.24 & 1.6 & 14 \\
\hline $\mathbf{2 0 1 6 / 3 0 9 3}$ & STAMPPND & oesters & 0.011 & 0.062 & 0.053 & 4.7 & 109 \\
\hline $\mathbf{2 0 1 6 / 3 0 9 6}$ & WESTKSRK & mosselen & 0.022 & 0.073 & 0.27 & 0.91 & 13 \\
\hline $\mathbf{2 0 1 6 / 3 0 9 9}$ & DOOVBMDN & mosselen & 0.014 & 0.029 & 0.17 & 1.3 & 9.2 \\
\hline $\mathbf{2 0 1 6 / 3 1 0 2}$ & OORT & mosselen & 0.035 & 0.094 & 0.34 & 0.92 & 13 \\
\hline $\mathbf{2 0 1 6 / 3 1 0 5}$ & DANTZGT & mosselen & 0.031 & 0.075 & 0.27 & 0.92 & 15 \\
\hline
\end{tabular}

$\mathrm{Q}=\mathrm{ISO} 17025$ 
Tabel 6. Gehalten aan spoorelementen in $\mathrm{mg} / \mathrm{kg}$ product (Chroom, Arseen en Nikkel), as, droge stof en asvrijdrooggewicht (AVDG) in \%

\begin{tabular}{|c|l|l|c|c|c|c|c|c|}
\hline LIMSnr. & DONAR code & Matrix & Chroom & Arseen & Nikkel & $\begin{array}{c}\text { Droge } \\
\text { stof } \\
(\%)\end{array}$ & $\begin{array}{c}\text { As } \\
(\%)\end{array}$ & $\begin{array}{c}\text { AVDG } \\
(\%)\end{array}$ \\
\hline & & & $Q$ & $Q$ & & Q & Q & \\
\hline $2016 / 3072$ & BURGHSWBBSS & mosselen & 0.18 & 1.7 & 0.26 & 17.9 & 2.5 & 15.4 \\
\hline $2016 / 3075$ & NUNNPJZWT & mosselen & 0.16 & 2.0 & 0.23 & 19.3 & 2.3 & 17.0 \\
\hline $2016 / 3078$ & YERSKVWTPS & mosselen & 0.18 & 1.5 & 0.22 & 14.8 & 2.5 & 12.3 \\
\hline $2016 / 3081$ & HOOGPTN & mosselen & 0.21 & 2.1 & 0.35 & 17.0 & 2.4 & 14.6 \\
\hline $2016 / 3084$ & HOEDKKKBI4 & mosselen & 0.26 & 1.7 & 0.46 & 12.0 & 2.1 & 9.9 \\
\hline $2016 / 3087$ & SLIJKGBISG18 & mosselen & 0.10 & 1.3 & 0.16 & 20.2 & 1.7 & 18.5 \\
\hline $2016 / 3090$ & DOMBBSD & mosselen & 0.20 & 2.0 & 0.30 & 17.7 & 2.3 & 15.4 \\
\hline $2016 / 3093$ & STAMPPND & oesters & 0.027 & 1.1 & 0.037 & 11.9 & 2.3 & 9.6 \\
\hline $2016 / 3096$ & WESTKSRK & mosselen & 0.18 & 1.3 & 0.27 & 11.9 & 2.4 & 9.5 \\
\hline $2016 / 3099$ & DOOVBMDN & mosselen & 0.16 & 1.2 & 0.24 & 17.9 & 2.0 & 15.9 \\
\hline $2016 / 3102$ & OORT & mosselen & 0.20 & 1.9 & 0.43 & 11.2 & 2.1 & 9.1 \\
\hline $2016 / 3105$ & DANTZGT & mosselen & 0.17 & 1.8 & 0.31 & 11.9 & 2.3 & 9.6 \\
\hline
\end{tabular}

$\mathrm{Q}=\mathrm{ISO} 17025$ 
Tabel 7. Gehalten aan PCB's en HCB in $\mu \mathrm{g} / \mathrm{kg}$ product, vet in \%

\begin{tabular}{|c|c|c|c|c|c|}
\hline LIMSnr. & DONAR-code & HCB & CB-138 & CB-153 & Vet(BD) \\
\hline & & $\boldsymbol{\mu g} / \mathbf{k g}$ & $\boldsymbol{\mu g} / \mathbf{k g}$ & $\boldsymbol{\mu g} / \mathbf{k g}$ & $\mathbf{\%}$ \\
\hline & & $\mathrm{Q}$ & $\mathrm{Q}$ & $\mathrm{Q}$ & $\mathrm{Q}$ \\
\hline $2016 / 3072$ & BURGHSWBBSS & $<0.04$ & 1.2 & 2.4 & 1.6 \\
\hline $2016 / 3075$ & NUNNPJZWT & $<0.05$ & 1.5 & 3.2 & 1.9 \\
\hline $2016 / 3078$ & YERSKVWTPS & $<0.05$ & 0.9 & 1.7 & 1.3 \\
\hline $2016 / 3081$ & HOOGPTN & $<0.05$ & 3.9 & 8.3 & 1.8 \\
\hline $2016 / 3084$ & HOEDKKKBI4 & $<0.04$ & 4.5 & 8.7 & 1.2 \\
\hline $2016 / 3087$ & SLIJKGBISG18 & 0.06 & 2.1 & 5.3 & 2.2 \\
\hline $2016 / 3090$ & DOMBBSD & $<0.04$ & 2.0 & 4.3 & 1.9 \\
\hline $2016 / 3093$ & STAMPPND & $<0.01$ & 0.3 & 1.6 & 1.4 \\
\hline $2016 / 3096$ & WESTKSRK & $<0.04$ & 0.8 & 1.5 & 0.9 \\
\hline $2016 / 3099$ & DOOVBMDN & $<0.05$ & 1.0 & 1.9 & 1.5 \\
\hline $2016 / 3102$ & OORT & $<0.03$ & 1.1 & 2.0 & 1.0 \\
\hline $2016 / 3105$ & DANTZGT & 0.2 & 1.0 & 1.9 & 1.1 \\
\hline
\end{tabular}

$\mathrm{Q}=$ ISO17025 
De resultaten van de IRM's (Interne Referentie Materialen), gemeten door Wageningen Marine Research, zijn gecontroleerd met betrekking tot overschrijdingen van de 2s- en 3s-grenzen van de door Wageningen Marine Research intern gehanteerde kwaliteitscontrolekaarten voor de betreffende elementen. Dit is weergegeven in bijlage 5. Indien de 3s-grens wordt overschreden wordt daarop, vastgelegd in ons kwaliteitssysteem, adequaat actie ondernomen. Bijlage 7 toont echter dat aan de metingen, in 2016 uitgevoerd door Wageningen Marine Research in de IRM's, de kwalificatie goed kan worden toegekend.

De resultaten van Quasimeme ringonderzoeken zijn weergegeven in bijlage 6.

Indien een z-score de kwalificatie 'unsatisfactory' heeft gekregen wordt daarop, vastgelegd in ons kwaliteitssysteem, adequaat actie ondernomen. Hierop vindt jaarlijks controle plaats door de Raad voor Accreditatie.

De betekenissen van de kwalificaties, zoals door Quasimeme toegekend, zijn als volgt:

Satisfactory: $\quad|Z|<2$, resultaat voldoet

Unsatisfactory: $\quad|Z|>3$, resultaat voldoet niet (adequate actie vereist)

Questionable: $\quad|Z|<3$, resultaat is twijfelachtig (geen actie vereist)

Consistent: er is een waarde $(x)<$ rapportagegrens door het deelnemend lab gerapporteerd, deze waarde was in overeenstemming met de assigned value (consensus waarde), bv. $<0.03$ gerapporteerd, terwijl assigned value 0.02 is

Inconsistent: $\quad$ er is een waarde $(x)<$ rapportagegrens door het deelnemend lab gerapporteerd, deze waarde was niet in overeenstemming met de assigned value (consensus waarde), bv. $<0.03$ gerapporteerd, terwijl assigned value 0.06 is

Blanc: geen z-score bepaald door Quasimeme (mogelijke oorzaken: te weinig laboratoria hebben resultaten gerapporteerd of de spreiding van de resultaten tussen de laboratoria onderling was te groot)

In 2016 is aan twee ringonderzoekrondes van Quasimeme deelgenomen (de labcode van Wageningen Marine Research is Q127).

De ringonderzoeken zijn binnen ons kwaliteitssysteem geëvalueerd en waar nodig zijn passende maatregelen genomen.

T.a.v. de toetsingscriteria op de resultaten van TNO Triskelion kan het volgende gezegd worden:

Wageningen Marine Research hanteert een maximum toelaatbare rsd van $15 \%$ voor metalen tussen de duplowaarden van een monster, geanalyseerd door TNO Triskelion. De resultaten van het oude IRM van WMR, gemeten door TNO Triskelion, voldoen niet aan de gestelde eisen. De duplo verschillen zijn te hoog voor koper en lood. Ook bij heranalyse van het IRM werden te hoge duplowaarden vastgesteld. Dit criterium voor duploverschillen werd dit jaar voor geen enkel mosselmonster overschreden.

Ook voldoen de analyses aan de gestelde eisen van het Triskelion kwaliteitssysteem, TNO Triskelion heeft alle resultaten van de metaalanalyses onder Q (ISO 17025 accreditatie) gerapporteerd met uitzondering van nikkel. De analyses worden daarom onder Q gerapporteerd in dit rapport.

TNO Triskelion neemt niet deel aan de ringonderzoeken van Quasimeme, de kwaliteit van hun analyses wordt echter wel geborgd door deelname aan andere ringonderzoeken, nl. die van FAPAS en IRMM. 
In bijlage 7 zijn de rapportagegrenzen en meetonzekerheden weergegeven.

De rapportagegrenzen voor de anorganische componenten en voor de metalen zijn vaste rapportagegrenzen die zijn vastgesteld uit de historie van de blanco bepalingen.

De rapportagegrenzen voor de organische componenten worden vastgesteld aan de hand van de laagst gemeten standaard.

De rapportagegrens is afhankelijk van de hoeveelheid ingewogen monster en is dus eigenlijk voor ieder monster verschillend, de compromis rapportagegrenzen zijn in bijlage 7 weergegeven.

De RMS (root mean square) wordt berekend volgens NEN 7779 als basis voor de gecombineerde meetonzekerheid (standard uncertainty) uit de resultaten van verschillende ringonderzoeken (verschillende matrices) van meerdere rondes $(n>8)$. De relatieve uitgebreide meetonzekerheid (expanded uncertainty) is gedefinieerd als twee maal de relatieve standard uncertainty. De relative standard uncertainty is weergegeven in bijlage 7. Hierin zijn de reproduceerbaarheid, de tussenmonster-spreiding en de methode juistheid verwerkt. Eventuele inhomogeniteit van het monster is hier niet in verwerkt, maar is bij ringonderzoekmonsters niet van toepassing.

Voor de rapportage aan OSPAR dient bij iedere meetwaarde de expanded uncertainty (95\% betrouwbaarheidsinterval) berekend te worden. De expanded uncertainty is gedefinieerd als tweemaal de standaard deviatie. Voor OSPAR dient dus een absolute meetonzekerheid gerapporteerd te worden. De berekening van de absolute expanded uncertainty is gebaseerd op onderstaande formules uit de OSPAR guideline voor de bepaling van de meetonzekerheid. De relative standard uncertainty (uitgedrukt in \%) wordt door Wageningen Marine Research als maat voor de vc gehanteerd. In bijlage 8.3 zijn zowel de relative standard uncertainty $(=\mathrm{vc})$ als de constant error $(=\mathrm{dc})$ opgenomen. Beide dienen als input in de formules voor de berekening van de absolute expanded uncertainty.

Formules uit de OSPAR quideline:

$s_{C}=\sqrt{d_{C}^{2}+\left(\frac{v_{c}}{100}\right)^{2} C^{2}}$

waarin:

$\mathrm{S}_{\mathrm{c}}=$ standard deviation (eenheid = eenheid van concentratie component)

$\mathrm{d}_{\mathrm{c}}=$ "combined constant error" (eenheid = eenheid van concentratie component)

$\mathrm{v}_{\mathrm{c}}=$ variatie coëfficiënt (eenheid= percentage)

$\mathrm{C}=$ concentratie van de component in het monster (meetwaarde)

$U_{c}=2 S_{c}$

waarin:

$\mathrm{U}_{\mathrm{c}}=$ (absolute) expanded uncertainty (eenheid = eenheid van concentratie component)

Voor componenten waarvoor geen deelname plaatsvindt aan ringonderzoeken is, indien mogelijk, de meetonzekerheid vastgesteld op basis van juistheidsbepaling en monsterinhomogeniteit. Voor componenten waarvoor zowel geen ringonderzoeken als geen referentiematerialen voorhanden zijn, kan de meetonzekerheid niet worden vastgesteld. Voor componenten waarvoor het aantal deelgenomen rondes aan ringonderzoeken minder bedraagt dan 8, kan nog geen meetonzekerheid worden vastgesteld volgens NEN 7779.

De resultaten van de kwaliteitscontrole voldoen aan de kwaliteitstandaarden van Wageningen Marine Research. 


\section{Conclusies}

Het onderzoek op fecale coliformen in de op 12 geselecteerde locaties aanwezige of uitgehangen mosselen leverde geen normoverschrijding van de mediaanwaarde op. Dit betekent dat er een gehalte van minder dan 300 fecale coliformen per $100 \mathrm{ml}$ schelpdiervlees en -vocht is aangetroffen in de monsters. Op vier locaties zijn enkele waarden van de vijfvoudige meting fecale coliformen verhoogd, namelijk locatie Hooge Platen (80, 40 f.c. $/ 100$ ml), locatie Hoedekenskerke (80, 20 f.c. /100 ml), Yerseke verwaterplaats $(120,240,280$ f.c. $/ 100 \mathrm{ml}$ ) en locatie Burghsluis tussen Westbout en Burghsluis (40 f.c. /100 ml).

Het aanvullend onderzoek op $E$. coli leverde geen normoverschrijdingen op van de mediaanwaarde, in alle monsters is $E$. coli onder de detectielimiet $(<20)$ gerapporteerd.

Uit de resultaten van het zintuiglijk waarnemingenonderzoek blijkt dat er geen zichtbare olie op of aan het oppervlakte water aanwezig is van de bemonsterde locaties en dat de subjectieve waarneming op geur en smaak van de gemonsterde schelpdieren geen afwijkingen vertonen.

De zuurgraad van de 12 locaties varieert tussen 7.42 (Oort, Waddenzee Oost) en 8.28 (Domburg Badstrand, Voordelta) en de temperatuur tussen 4.7 en $11.6^{\circ} \mathrm{C}$ (resp. Yerseke verwaterplaats en Stamperplaat)

Dit verschil is te verklaren door het monsteren op verschillende data (met een maand spreiding) en de verschillende waterdiepten ter plaatse. Het patroon is een beeld dat overeenkomstig is met de verwachtingen op basis van overige monitoringdata (http://live.waterbase.nl).

De saliniteit varieert tussen 15.2 (Kop van Goeree nabij Slijkgat, Voordelta) en 31.6 (Domburg Badstrand, Voordelta). Bij het Slijkgat is een lage saliniteit gemeten, zeer waarschijnlijk is dit veroorzaakt door de hoge zoetwaterlast als gevolg van spuien, er wordt bij de monstername geen rekening gehouden met het getij of spui-activiteiten. Het oppervlaktewater van de Westerschelde heeft nabij locatie Hoedekenskerke een saliniteit van 20.2 en bij Hooge Platen 25.2. Dit is te verklaren door de saliniteitsgradiënt van de Westerschelde.

De gehalten aan gesuspendeerde stoffen fluctueren tussen 1.6 (Stampersplaat noord, Grevelingen) en $43.9 \mathrm{mg} / \mathrm{l}$ (Domburg Badstrand, Voordelta).

De kleurintensiteit varieerde tussen 0 (Westkom, Waddenzee / Doove Balg, Waddenzee) en 25 op de Pt/Co- schaal (Oort, Waddenzee Oost).

De contaminanten gehalten vallen allemaal binnen het verwachtingspatroon op basis van de afgelopen jaren. Voor Cadmium in de Westerschelde op locatie Hoedekenskerke geldt dat deze op product basis $0.89 \mathrm{mg} \mathrm{Cd} / \mathrm{kg}$ schelpdierproduct bedraagt. De consumptienorm hiervoor is $1 \mathrm{mg} \mathrm{Cd} / \mathrm{kg}$, waardoor het een aandachtspunt betreft voor eventuele toekomstige visserij activiteiten.

Monitoring van 12 schelpdierwater locaties is conform de schelpdierwater richtlijn uitgevoerd. Analyses zijn binnen de gestelde randvoorwaarden uitgevoerd. Op basis van de resultaten kan worden gesteld dat de locaties binnen de gestelde voorwaarden van de richtlijn vallen. 


\section{Literatuur}

Anoniem (1983) Besluit kwaliteitsdoelstellingen en metingen oppervlaktewateren. Staatsblad van het Koninkrijk der Nederlanden, jaargang 1983. Stb. nr. 3-11-'83. gewijzigd bij besluit van 22 januari 1991, Staatsblad 45 en besluit van 3 februari 1994, Stb 89.

Anoniem (2005) Verordening (EG) Nr. 2073/2005 van de commissie van 15 november 2005 inzake microbiologische criteria voor levensmiddelen.

Anoniem (2006) Verordening (EG) Nr. 1881/2006 van de commissie van 19 december 2006 tot vaststelling van de maximumgehalten aan bepaalde verontreinigingen in levensmiddelen

Anoniem (2008) Verordening (EG) Nr. 629/2008 van de commissie van 2 juli 2008 tot wijziging van Verordening (EG) nr. 1881/2006 tot vaststelling van maximumgehalten aan bepaalde verontreinigingen in levensmiddelen.

APHA (2005) Standard methods for examination of water \& wastewater APHA, AWWA, WEF; 21 Edition 2005 page 2-48 salinity.

Anoniem (2010) EU Working Group on Microbiological monitoring of Bivalve Mollusc (2006) Good Practice Guide on Microbiological Monitoring of Bivalve Mollusc Harvesting Areas Guide to Good Practice: Technical Application, Issue 4, CEFAS Augustus 2010.

Glorius S., A. van Gool, C. van Zweeden, Poelman, M. (2013) Interreg Safeguard - Food safety mapping of mussels and oysters (Crassostrea gigas) in the Dutch Wadden Sea. IMARES Report In prep.

Mooijman K.A. Poelman M., Stegeman H., Warmerdam C., Teunis P.F.M. en A.M. de Roda Husman (2007) Validation and comparison of methods for enumeration of faecal coliforms and Escherichia coli in bivalve molluscs. RIVM report 330310001/2006

Roex, E., M. van den Heuvel-Greve (2010) Monitoring van bioaccumulerende prioritaire KRW stoffen; in water of in biota? Deltares rapport 1001-0154, 21 januari 2010. 


\section{$5 \quad$ Kwaliteitsborging}

Het chemisch laboratorium te IJmuiden beschikt over een NEN-EN-ISO/IEC 17025:2005 accreditatie voor testlaboratoria met nummer L097. Deze accreditatie is geldig tot 1 april 2021 en is voor het eerst verleend op 27 maart 1997; deze accreditatie is verleend door de Raad voor Accreditatie. Het chemisch laboratorium heeft hierdoor aangetoond in staat te zijn op technisch bekwame wijze valide resultaten te leveren en te werken volgens de ISO17025 norm. De scope (L097) met de geaccrediteerde analysemethoden is te vinden op de website van de Raad voor Accreditatie (www.rva.nl).

Op grond van deze accreditatie is het kwaliteitskenmerk $Q$ toegekend aan resultaten van componenten die op de scope zijn vermeld, mits aan alle kwaliteitseisen is voldaan. Het kwaliteitskenmerk $Q$ staat vermeld in de tabellen met de onderzoeksresultaten. Indien het kwaliteitskenmerk $Q$ niet staat vermeld is de reden hiervan vermeld.

De kwaliteit van de analysemethoden wordt op verschillende manieren gewaarborgd:

- $\quad$ Bij iedere meetserie wordt een eerstelijnscontrole uitgevoerd: de resultaten van elke (serie van) meting(en) worden gecontroleerd door het gebruik van gecertificeerd en/of intern referentiemateriaal. Deze gegevens worden in kwaliteitscontrolekaarten bijgehouden. De "gecertificeerde" gehalten en de waarden van de waarschuwingsgrens (tweemaal standaarddeviatie) van de gebruikte referentiematerialen zijn weergegeven in bijlage 8.1 .

- $\quad$ De juistheid van de analysemethoden wordt regelmatig getoetst door deelname aan ringonderzoeken waaronder die georganiseerd door QUASIMEME (derdelijnscontrole). Resultaten van de rondes zijn weergegeven in bijlage 8.2. Indien geen ringonderzoek voorhanden is, wordt een tweedelijnscontrole (blind monster) uitgevoerd.

- $\quad$ Naast de lijnscontroles worden de volgende algemene kwaliteitscontroles uitgevoerd:

- Blanco onderzoek

- $\quad$ Terugvinding (recovery)

- $\quad$ Interne standaard voor borging opwerkmethode

- $\quad$ Injectie standaard

- $\quad$ Gevoeligheid

Alle controles staan beschreven in Wageningen Marine Research ISW 2.10.2.105.

Indien sprake is van onbeheerste kwaliteit worden passende maatregelen genomen waarop jaarlijks controle plaatsvindt door de RvA.

Op speciaal verzoek van RWS zijn ook rapportagegrenzen en meetonzekerheden per component gerapporteerd. Deze zijn weergegeven in bijlage 8.3.

Daarnaast beschikt Wageningen Marine Research over een ISO 9001:2008 gecertificeerd kwaliteitsmanagementsysteem (certificaatnummer: 187378-2015-AQ-NLD-RvA). Dit certificaat is geldig tot 15 september 2018. De organisatie is gecertificeerd sinds 27 februari 2001. De certificering is uitgevoerd door DNV Certification B.V.

TNO Triskelion te Zeist

Het TNO laboratorium beschikt over een geldig ISO/IEC 17025 certificaat voor testlaboratoria met nummer L546 en is geaccrediteerd voor de bepaling van de te analyseren metalen arseen, cadmium, chroom, koper, lood en zink in vismatrix. De scoop is te vinden op de website van de Raad voor Accreditatie www.rva.nl en is geldig tot 1 november 2020.

Om de kwaliteit van de analysen te waarborgen en eventuele trendbreuk met metingen van voorgaande jaren inzichtelijk te maken is door Wageningen Marine Research een intern referentiemateriaal (IRM) meegestuurd. 


\section{Verantwoording}

Rapport C072/17

Projectnummer: 4316100056

Dit rapport is met grote zorgvuldigheid tot stand gekomen. De wetenschappelijke kwaliteit is intern getoetst door een collega-onderzoeker en het verantwoordelijk lid van het managementteam van Wageningen Marine Research

Akkoord:

Dr. D. Slijkerman

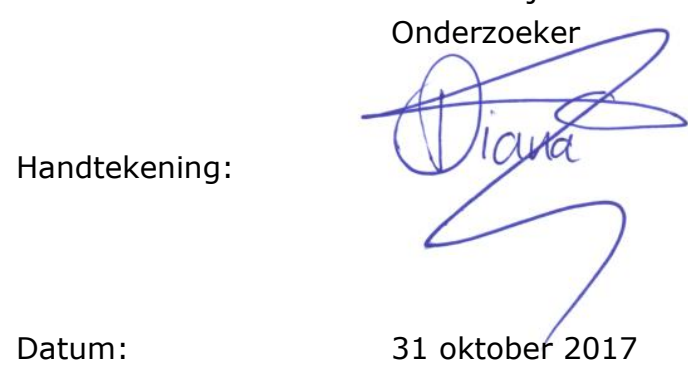

Akkoord:

Dr. ir. T.P. Bult

Director

Handtekening:

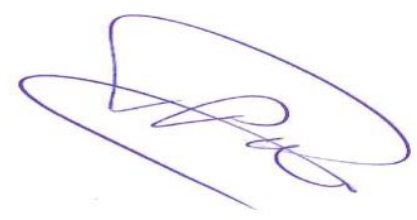

Datum:

31 oktober 2017 


\section{Bijlage 1 Monsterlocaties Zuidelijk Westelijke Delta}

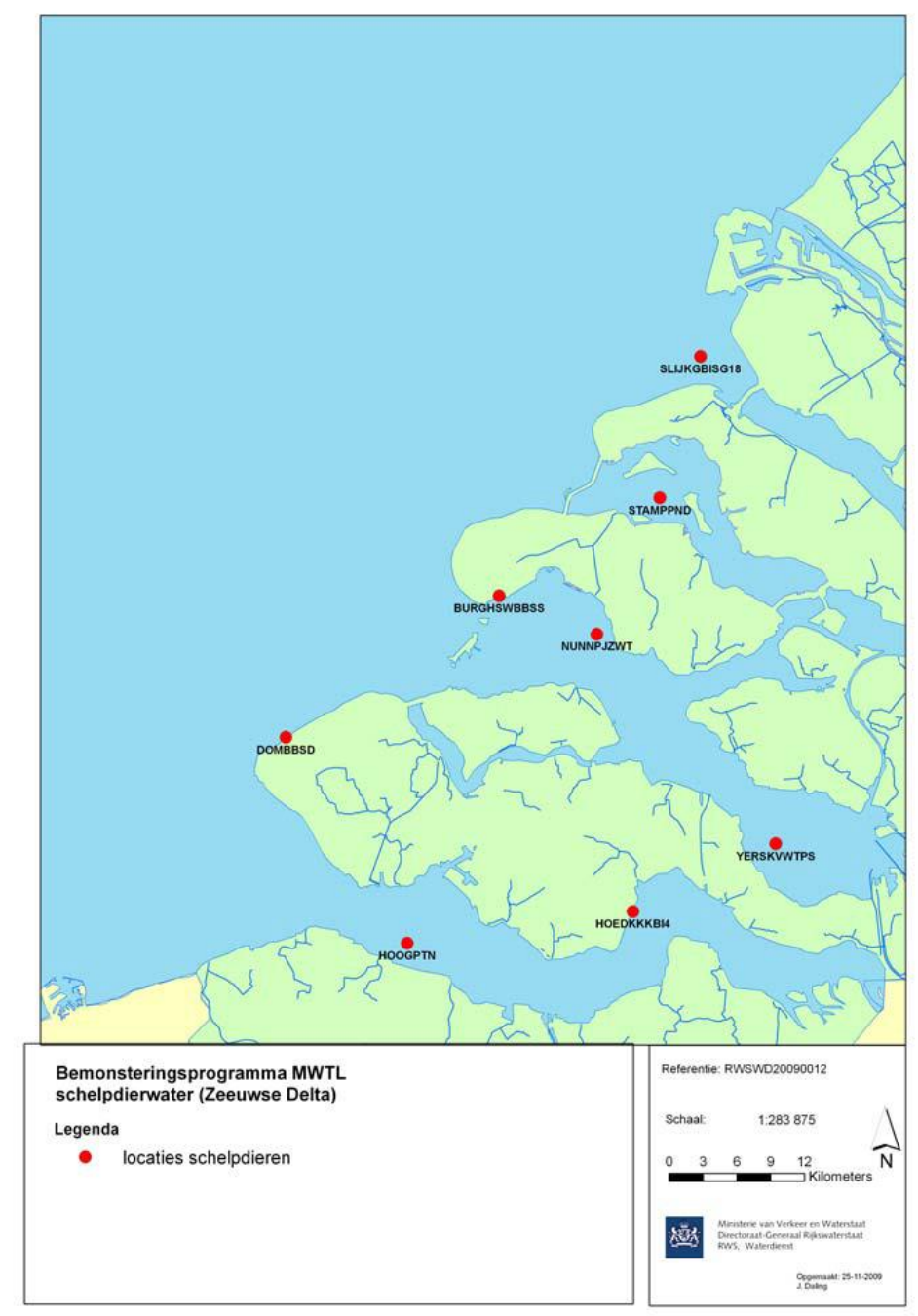

Bron: Projectplan Monitoring schelpdierwater (24 oktober 2013)

\begin{tabular}{|l|l|l|}
\hline DONARCODE & Gebied & Locatie \\
\hline HOEDKKKBI4 & Westerschelde & nabij Hoedekenskerke \\
\hline HOOGPTN & Westerschelde & Hooge Platen (nabij Vlissingen) \\
\hline DOMBBSD & $\begin{array}{l}\text { Kustwater voor } \\
\text { Domburg }\end{array}$ & $\begin{array}{l}\text { Domburg (aan stenig strand nabij } \\
\text { Kinkerduin) }\end{array}$ \\
\hline YERSKVWTPS & Oosterschelde & Yerseke Bank 316 (verwaterplaats) \\
\hline NUNNPJZWT & Oosterschelde & Hammen 55 (Nunnenplaatje zuidwest) \\
\hline BURGHSWBBSS) & Oosterschelde & $\begin{array}{l}\text { Hammen 10 Burghsluis tussen Westbout } \\
\text { en Burghsluis) }\end{array}$ \\
\hline STAMPPND & Grevelingen & Stampersplaat noord \\
\hline SLIJKGBISG18 & $\begin{array}{l}\text { Kustwater voor } \\
\text { Kop van Goeree }\end{array}$ & Slijkgat \\
\hline
\end{tabular}




\section{Bijlage 2 Monsterlocaties Waddenzee}

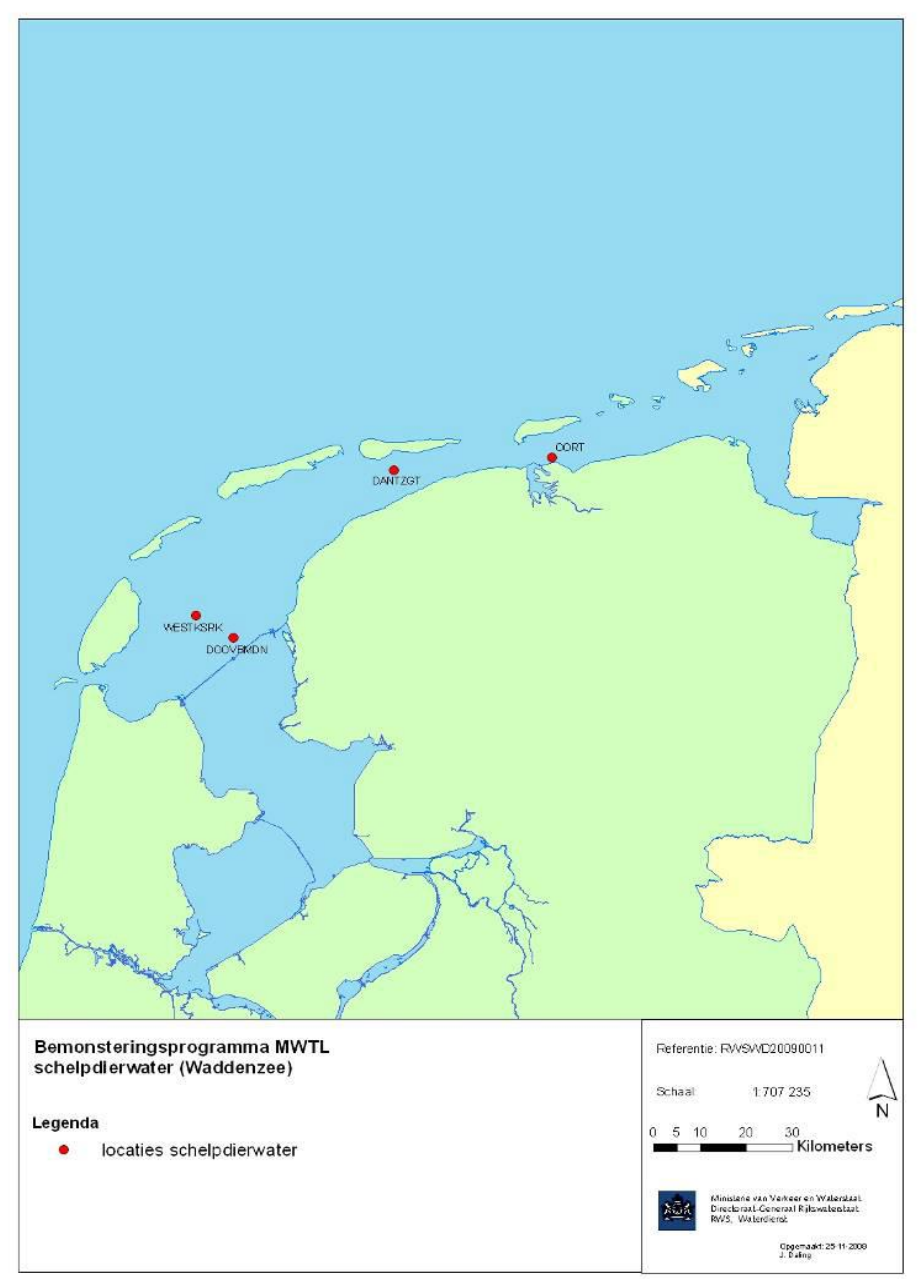

Bron: Projectplan Monitoring schelpdierwater (24 oktober 2013)

\begin{tabular}{|l|l|l|}
\hline DONARCODE & Gebied & Locatie \\
\hline WESTKSRK & Waddenzee, West & Westkom/Scheurrak \\
\hline DOOVBMDN & Waddenzee, West & Doove Balg midden \\
\hline DANTZGT & Waddenzee, Oost & Dantziggat \\
\hline OORT & Waddenzee, Oost & Zoutkamperlaag, Oort \\
\hline
\end{tabular}




\section{Bijlage 3 Gehalten aan spoorelementen in schelpdieren 2016}

\begin{tabular}{|c|c|c|c|c|c|c|c|c|c|c|c|}
\hline & & & & $\begin{array}{c}\mathrm{Kwik} \\
\mathrm{mg} / \mathrm{kg}\end{array}$ & $\begin{array}{c}\text { Cadmium } \\
\mathrm{mg} / \mathrm{kg}\end{array}$ & $\begin{array}{l}\text { Lood } \\
\mathrm{mg} / \mathrm{kg}\end{array}$ & $\begin{array}{l}\text { Koper } \\
\mathrm{mg} / \mathrm{kg}\end{array}$ & $\begin{array}{c}\text { Zink } \\
\mathrm{mg} / \mathrm{kg}\end{array}$ & $\begin{array}{c}\text { Chroom } \\
\mathrm{mg} / \mathrm{kg}\end{array}$ & $\begin{array}{c}\text { Arseen } \\
\mathrm{mg} / \mathrm{kg}\end{array}$ & $\begin{array}{l}\text { Nikkel } \\
\mathrm{mg} / \mathrm{kg}\end{array}$ \\
\hline RQ20160928/063 & $2016 / 3072$ & Schelpdiervlees & Oosterschelde Burghsluis & 0.10 & 0.22 & 1.4 & 7.8 & 78 & 1.0 & 9.5 & 1.5 \\
\hline RQ20160930/064 & $2016 / 3075$ & Schelpdiervlees & $\begin{array}{c}\text { Oosterschelde: Nunnenplaatje } \\
\text { zuidwest }\end{array}$ & 0.12 & 0.27 & 1.2 & 8.4 & 67 & 0.89 & 11 & 1.3 \\
\hline RQ20160930/065 & $2016 / 3078$ & Schelpdiervlees & $\begin{array}{l}\text { Oosterschelde: Yerseke } \\
\text { verwaterplaats }\end{array}$ & 0.089 & 0.21 & 1.1 & 6.7 & 73 & 1.0 & 8.4 & 1.2 \\
\hline RQ20160930/066 & $2016 / 3081$ & Schelpdiervlees & Westerschelde: Hooge Platen & 0.13 & 1.5 & 1.8 & 7.8 & 89 & 1.2 & 12 & 2.0 \\
\hline RQ20160930/067 & $2016 / 3084$ & Schelpdiervlees & $\begin{array}{c}\text { Westerschelde: } \\
\text { Hoedekenskerke Boei4 }\end{array}$ & 0.17 & 5.0 & 2.2 & 7.3 & 117 & 1.5 & 9.5 & 2.6 \\
\hline RQ20160930/068 & $2016 / 3087$ & Schelpdiervlees & $\begin{array}{c}\text { Voordelta: Kop van Goeree } \\
\text { Slijkgat SG18 }\end{array}$ & 0.084 & 0.44 & 1.2 & 10 & 56 & 0.56 & 7.3 & 0.89 \\
\hline RQ20160930/069 & $2016 / 3090$ & Schelpdiervlees & Voordelta: Domburg badstrand & 0.13 & 0.33 & 1.3 & 8.9 & 78 & 1.1 & 11 & 1.7 \\
\hline RQ20160930/070 & $2016 / 3093$ & Schelpdiervlees & $\begin{array}{l}\text { Grevelingenmeer: } \\
\text { Stampersplaat noord }\end{array}$ & 0.061 & 0.35 & 0.30 & 26 & 609 & 0.15 & 6.1 & 0.21 \\
\hline RQ20160930/071 & 2016/3096 & Schelpdiervlees & $\begin{array}{c}\text { Waddenzee west: Westkom / } \\
\text { Scheurrak }\end{array}$ & 0.12 & 0.41 & 1.5 & 5.1 & 73 & 1.0 & 7.3 & 1.5 \\
\hline RQ20160930/072 & 2016/3099 & Schelpdiervlees & $\begin{array}{l}\text { Waddenzee west: Doovebalg } \\
\text { midden }\end{array}$ & 0.078 & 0.16 & 0.95 & 7.3 & 51 & 0.89 & 6.7 & 1.3 \\
\hline RQ20160930/073 & $2016 / 3102$ & Schelpdiervlees & $\begin{array}{c}\text { Waddenzee oost: } \\
\text { Zoutkamperlaag, Oort }\end{array}$ & 0.20 & 0.53 & 1.9 & 5.1 & 73 & 1.1 & 11 & 2.4 \\
\hline RQ20160930/074 & $2016 / 3105$ & Schelpdiervlees & Waddenzee oost: Dantziggat & 0.17 & 0.42 & 1.5 & 5.1 & 84 & 0.95 & 10 & 1.7 \\
\hline
\end{tabular}


Bijlage 3B. Gehalten aan spoorelementen in $\mathrm{mg} / \mathrm{kg}$ op

asvrijdrooggewichtbasis

\begin{tabular}{|c|c|c|c|c|c|c|c|c|c|c|c|}
\hline & \multirow{3}{*}{$\begin{array}{c}\begin{array}{c}\text { Kwik } \\
\mathrm{mg} / \mathrm{kg}\end{array} \\
0.12 \\
\end{array}$} & \multirow{3}{*}{$\begin{array}{c}\begin{array}{c}\text { Cadmium } \\
\mathrm{mg} / \mathrm{kg}\end{array} \\
0.26\end{array}$} & \multirow{3}{*}{$\begin{array}{c}\begin{array}{c}\text { Lood } \\
\mathrm{mg} / \mathrm{kg}\end{array} \\
1.6 \\
\end{array}$} & \multirow{3}{*}{$\begin{array}{c}\begin{array}{c}\text { Koper } \\
\mathrm{mg} / \mathrm{kg}\end{array} \\
9.1\end{array}$} & \multirow{3}{*}{$\begin{array}{c}\begin{array}{c}\text { Zink } \\
\mathrm{mg} / \mathrm{kg}\end{array} \\
91\end{array}$} & \multirow{3}{*}{$\begin{array}{c}\begin{array}{c}\text { Chroom } \\
\mathrm{mg} / \mathrm{kg}\end{array} \\
1.2\end{array}$} & \multirow{3}{*}{ 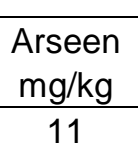 } & \multirow{3}{*}{$\begin{array}{c}\begin{array}{c}\text { Nikke } \\
\mathrm{mg} / \mathrm{kg}\end{array} \\
1.7\end{array}$} \\
\hline & & & & & & & & & & & \\
\hline RQ20160928/063 & $2016 / 3072$ & Schelpdiervlees & Oosterschelde Burghsluis & & & & & & & & \\
\hline RQ20160930/064 & $2016 / 3075$ & Schelpdiervlees & $\begin{array}{c}\text { Oosterschelde: Nunnenplaatje } \\
\text { zuidwest }\end{array}$ & 0.14 & 0.32 & 1.4 & 9.7 & 78 & 1.0 & 13 & 1.5 \\
\hline RQ20160930/065 & $2016 / 3078$ & Schelpdiervlees & $\begin{array}{c}\text { Oosterschelde: Yerseke } \\
\text { verwaterplaats }\end{array}$ & 0.10 & 0.25 & 1.3 & 7.8 & 84 & 1.2 & 10 & 1.4 \\
\hline RQ20160930/066 & $2016 / 3081$ & Schelpdiervlees & Westerschelde: Hooge Platen & 0.16 & 1.7 & 2.1 & 9.1 & 104 & 1.4 & 14 & 2.3 \\
\hline RQ20160930/067 & $2016 / 3084$ & Schelpdiervlees & $\begin{array}{c}\text { Westerschelde: Hoedekenskerke } \\
\text { Boei4 }\end{array}$ & 0.19 & 5.8 & 2.6 & 8.4 & 136 & 1.7 & 11 & 3.0 \\
\hline RQ20160930/068 & $2016 / 3087$ & Schelpdiervlees & $\begin{array}{c}\text { Voordelta: Kop van Goeree } \\
\text { Slijkgat SG18 }\end{array}$ & 0.10 & 0.51 & 1.4 & 12 & 65 & 0.65 & 8.4 & 1.0 \\
\hline RQ20160930/069 & $2016 / 3090$ & Schelpdiervlees & Voordelta: Domburg badstrand & 0.15 & 0.38 & 1.6 & 10 & 91 & 1.3 & 13 & 1.9 \\
\hline RQ20160930/070 & $2016 / 3093$ & Schelpdiervlees & $\begin{array}{c}\text { Grevelingenmeer: Stampersplaat } \\
\text { noord }\end{array}$ & 0.071 & 0.40 & 0.34 & 31 & 708 & 0.18 & 7.1 & 0.24 \\
\hline RQ20160930/071 & $2016 / 3096$ & Schelpdiervlees & $\begin{array}{c}\text { Waddenzee west: Westkom / } \\
\text { Scheurrak }\end{array}$ & 0.14 & 0.47 & 1.8 & 5.9 & 84 & 1.2 & 8.4 & 1.8 \\
\hline RQ20160930/072 & 2016/3099 & Schelpdiervlees & $\begin{array}{l}\text { Waddenzee west: Doovebalg } \\
\text { midden }\end{array}$ & 0.091 & 0.19 & 1.1 & 8.4 & 60 & 1.0 & 7.8 & 1.6 \\
\hline RQ20160930/073 & $2016 / 3102$ & Schelpdiervlees & $\begin{array}{c}\text { Waddenzee oost: } \\
\text { Zoutkamperlaag, Oort }\end{array}$ & 0.23 & 0.61 & 2.2 & 6.0 & 84 & 1.3 & 12 & 2.8 \\
\hline RQ20160930/074 & $2016 / 3105$ & Schelpdiervlees & Waddenzee oost: Dantziggat & 0.20 & 0.49 & 1.8 & 6.0 & 97 & 1.1 & 12 & 2.0 \\
\hline
\end{tabular}




\section{Bijlage 4 PCB's en HCB gehalten in schelpdieren 2016}

Gehalten PCB 153, 138 en HCB in $\mu \mathrm{g} / \mathrm{kg}$ op vetbasis

\begin{tabular}{|l|l|l|l|c|c|c|}
\hline LIMS-Nr & \multicolumn{1}{|c|}{ Matrix } & \multicolumn{1}{|c|}{ Locatie } & Soort & HCB & CB-153 & CB-138 \\
\hline & & & & $\mu \mathrm{g} / \mathrm{kg}$ & $\mu \mathrm{kg}$ & $\mu \mathrm{kg} / \mathrm{kg}$ \\
\hline $2016 / 3072$ & Schelpdiervlees & Oosterschelde Burghsluis & Mosselen & $<2.5$ & 150 & 75 \\
\hline $2016 / 3075$ & Schelpdiervlees & $\begin{array}{l}\text { Oosterschelde: Nunnenplaatje } \\
\text { zuidwest }\end{array}$ & Mosselen & $<2.6$ & 168 & 79 \\
\hline $2016 / 3078$ & Schelpdiervlees & $\begin{array}{l}\text { Oosterschelde: Yerseke } \\
\text { verwaterplaats }\end{array}$ & Mosselen & $<3.8$ & 131 & 69 \\
\hline $2016 / 3081$ & Schelpdiervlees & Westerschelde: Hooge Platen & Mosselen & $<2.8$ & 461 & 217 \\
\hline $2016 / 3084$ & Schelpdiervlees & $\begin{array}{l}\text { Westerschelde: } \\
\text { Hoedekenskerke Boei4 }\end{array}$ & Mosselen & $<3.3$ & 725 & 375 \\
\hline $2016 / 3087$ & Schelpdiervlees & $\begin{array}{l}\text { Voordelta: Kop van Goeree } \\
\text { Slijkgat SG18 }\end{array}$ & Mosselen & 2.7 & 241 & 95 \\
\hline $2016 / 3090$ & Schelpdiervlees & Voordelta: Domburg badstrand & Mosselen & $<2.1$ & 226 & 105 \\
\hline $2016 / 3093$ & Schelpdiervlees & $\begin{array}{l}\text { Grevelingenmeer: } \\
\text { Stampersplaat noord }\end{array}$ & Oesters & $<0.7$ & 114 & 21 \\
\hline $2016 / 3096$ & Schelpdiervlees & $\begin{array}{l}\text { Waddenzee west: Westkom / } \\
\text { Scheurrak }\end{array}$ & Mosselen & $<4.4$ & 167 & 89 \\
\hline $2016 / 3099$ & Schelpdiervlees & $\begin{array}{l}\text { Waddenzee west: Doovebalg } \\
\text { midden }\end{array}$ & Mosselen & $<3.3$ & 127 & 67 \\
\hline $2016 / 3102$ & Schelpdiervlees & $\begin{array}{l}\text { Waddenzee oost: } \\
\text { Zoutkamperlaag, Oort }\end{array}$ & Mosselen & $<3$ & 200 & 110 \\
\hline $2016 / 3105$ & Schelpdiervlees & Waddenzee oost: Dantziggat & Mosselen & 18.2 & 173 & 91 \\
\hline
\end{tabular}




\section{Bijlage 5 Resultaten referentiematerialen}

Bijlage 5: Validatiegegevens analysemethoden

\section{Resultaten referentiematerialen}

\begin{tabular}{|c|c|c|c|c|c|c|c|c|c|}
\hline Component & Referentiemateriaal & $\begin{array}{c}\text { WMR-waarde } \\
\text { in } 2016\end{array}$ & $\begin{array}{c}\mathrm{n} \\
\text { in } \\
2016\end{array}$ & $\begin{array}{c}\text { WMR-waarde } \\
\text { QC-kaart }\end{array}$ & $\begin{array}{c}\mathrm{n} \\
\text { totaal }\end{array}$ & $\mathrm{ng} / \mathrm{dg}$ & $\begin{array}{c}\text { gecertificeerde } \\
\text { waarde }\end{array}$ & eenheid & kwalificatie \\
\hline Kwik & IRM Schol 2004/2069 & $\begin{array}{c}0.0575 \pm \\
0.0029\end{array}$ & 6 & $\begin{array}{c}0.0585 \pm \\
0.0030\end{array}$ & 40 & $\mathrm{ng}$ & n.v.t. & $\mathrm{mg} / \mathrm{kg}$ & goed \\
\hline Kwik & Oyster Tissue NIST1566b & $\begin{array}{c}0.0386 \pm \\
0.0011\end{array}$ & 6 & $\begin{array}{c}0.0377 \pm \\
0.0017\end{array}$ & 57 & $\mathrm{dg}$ & $\begin{array}{c}0.0371 \pm \\
0.0013\end{array}$ & $\mathrm{mg} / \mathrm{kg}$ & goed \\
\hline Dry-weight & $\begin{array}{l}\text { IRM 2005/0775 } \\
\text { Haring/makreel }\end{array}$ & $70.08 \pm 0.18$ & 9 & $70.00 \pm 0.252$ & 245 & $\mathrm{ng}$ & n.v.t. & $\%$ & goed \\
\hline Ash-Weight & IRM 2002/0757 Mosselen & $1.57 \pm 0.02$ & 3 & $1.58 \pm 0.04$ & 83 & $\mathrm{ng}$ & n.v.t. & $\%$ & goed \\
\hline Total-Lipid & $\begin{array}{l}\text { IRM 2005/0775 } \\
\text { Haring/makreel }\end{array}$ & $11.49 \pm 0.12$ & 16 & $11.54 \pm 0.14$ & 183 & $\mathrm{ng}$ & n.v.t. & $\%$ & Goed \\
\hline CB153 & IRM 2014/004 aal & $313 \pm 22$ & 10 & $317 \pm 21$ & 12 & $\mathrm{ng}$ & n.v.t. & $\mu \mathrm{g} / \mathrm{kg}$ & geen \\
\hline CB138 & IRM 2014/004 aal & $150.7 \pm 8.6$ & 10 & $152.1 \pm 8.5$ & 12 & $\mathrm{ng}$ & n.v.t. & $\mu \mathrm{g} / \mathrm{kg}$ & geen \\
\hline HCBD & IRM 2014/004 aal & $6.52 \pm 0.57$ & 11 & $6.61 \pm 0.56$ & 13 & $\mathrm{ng}$ & n.v.t. & $\mu \mathrm{g} / \mathrm{kg}$ & geen \\
\hline $\mathrm{HCB}$ & IRM 2014/004 aal & $15.6 \pm 1.7$ & 12 & $15.5 \pm 1.5$ & 15 & $\mathrm{ng}$ & n.v.t. & $\mu \mathrm{g} / \mathrm{kg}$ & geen \\
\hline
\end{tabular}




\section{Bijlage 6 Resultaten Ringonderzoek Quasimeme in biota}

\section{Bijlage 6: Validatiegegevens analysemethoden}

\section{Resultaten Ringonderzoek Quasimeme in biota}

labcode: Q127 IMARES

\begin{tabular}{|c|c|c|c|c|c|c|c|c|c|}
\hline Group & Round & Period & Matrix & Determinand & Unit & $\begin{array}{c}\text { Z- } \\
\text { score }\end{array}$ & Qualification & Comment & accreditatie \\
\hline BT1 & 2016.01 & $\begin{array}{l}\text { april } \\
2016 \\
\end{array}$ & QTM109BT & Dry-weight & $\%$ & -0.3 & Satisfactory & Quasimeme & ja \\
\hline BT1 & 2016.01 & $\begin{array}{l}\text { april } \\
2016\end{array}$ & QTM110BT & Dry-weight & $\%$ & 0.0 & Satisfactory & Quasimeme & ja \\
\hline BT1 & 2016.02 & $\begin{array}{c}\text { nov } \\
2016 \\
\end{array}$ & QTM112BT & Dry-weight & $\%$ & 0.0 & Satisfactory & Quasimeme & ja \\
\hline BT1 & 2016.02 & $\begin{array}{c}\text { nov } \\
2016\end{array}$ & QTM113BT & Dry-weight & $\%$ & -0.2 & Satisfactory & Quasimeme & ja \\
\hline BT1 & 2016.01 & $\begin{array}{l}\text { april } \\
2016 \\
\end{array}$ & QTM110BT & Ash-Weight & $\%$ & -0.3 & Satisfactory & Quasimeme & ja \\
\hline BT1 & 2016.01 & $\begin{array}{l}\text { april } \\
2016\end{array}$ & QTM110BT & Total-Lipid & $\%$ & -0.1 & Satisfactory & Quasimeme & ja \\
\hline BT1 & 2016.02 & $\begin{array}{c}\text { nov } \\
2016 \\
\end{array}$ & QTM112BT & Total-Lipid & $\%$ & 0.0 & Satisfactory & Quasimeme & ja \\
\hline BT1 & 2016.02 & $\begin{array}{c}\text { nov } \\
2016 \\
\end{array}$ & QTM112BT & Kwik & $\mu \mathrm{g} / \mathrm{kg}$ & 1.9 & Satisfactory & Quasimeme & ja \\
\hline BT1 & 2016.02 & $\begin{array}{c}\text { nov } \\
2016 \\
\end{array}$ & QTM113BT & Kwik & $\mu \mathrm{g} / \mathrm{kg}$ & 1.1 & Satisfactory & Quasimeme & ja \\
\hline BT2 & 2015.02 & $\begin{array}{c}\text { nov } \\
2015 \\
\end{array}$ & QOR124BT & CB153 & $\mu \mathrm{g} / \mathrm{kg}$ & -0.17 & Satisfactory & Quasimeme & ja \\
\hline BT2 & 2015.02 & $\begin{array}{c}\text { nov } \\
2015 \\
\end{array}$ & QOR125BT & CB153 & $\mu \mathrm{g} / \mathrm{kg}$ & 0.01 & Satisfactory & Quasimeme & ja \\
\hline BT2 & 2015.02 & $\begin{array}{c}\text { nov } \\
2015 \\
\end{array}$ & QOR124BT & CB138 & $\mu \mathrm{g} / \mathrm{kg}$ & -0.96 & Satisfactory & Quasimeme & ja \\
\hline BT2 & 2015.02 & $\begin{array}{c}\text { nov } \\
2015\end{array}$ & QOR125BT & CB138 & $\mu \mathrm{g} / \mathrm{kg}$ & -0.73 & Satisfactory & Quasimeme & ja \\
\hline BT2 & 2015.02 & $\begin{array}{c}\text { nov } \\
2015 \\
\end{array}$ & QOR125BT & $\mathrm{HCB}$ & $\mu \mathrm{g} / \mathrm{kg}$ & 0.48 & Satisfactory & Quasimeme & ja \\
\hline BT2 & 2015.02 & $\begin{array}{c}\text { nov } \\
2015 \\
\end{array}$ & QOR124BT & $\mathrm{HCB}$ & $\mu \mathrm{g} / \mathrm{kg}$ & 0.61 & Satisfactory & Quasimeme & ja \\
\hline
\end{tabular}




\section{Bijlage 7 Rapportagegrenzen en meetonzekerheid}

\section{Rapportagegrenzen en meetonzekerheid}

\begin{tabular}{|c|c|c|c|c|c|c|c|}
\hline Component & $\begin{array}{l}\text { rapportage- } \\
\text { grens }\end{array}$ & $\begin{array}{c}\text { detectie- } \\
\text { limiet }\end{array}$ & unit & $\mathrm{ng} / \mathrm{dg}$ & $\begin{array}{c}\text { VC } \\
\text { rel. standard uncertainty (\%) }\end{array}$ & $\mathrm{n}$ & $\mathrm{dc}$ \\
\hline PCB153 & 0.16 & 0.08 & $\mu \mathrm{g} / \mathrm{kg}$ & $\mathrm{ng}$ & 12.5 & 8 & 0 \\
\hline PCB138 & 0.16 & 0.08 & $\mu \mathrm{g} / \mathrm{kg}$ & $\mathrm{ng}$ & 13.0 & 8 & 0 \\
\hline HCBD & 0.01 & 0.004 & $\mu \mathrm{g} / \mathrm{kg}$ & $\mathrm{ng}$ & 7.5 & 8 & 0 \\
\hline $\mathrm{HCB}$ & 0.01 & 0.004 & $\mu \mathrm{g} / \mathrm{kg}$ & $\mathrm{ng}$ & 10.6 & 8 & 0 \\
\hline Kwik & 0.0008 & 0.0004 & $\mathrm{mg} / \mathrm{kg}$ & $\mathrm{ng}$ & 16.8 & 16 & 0 \\
\hline Dry-weight & 0.00037 & 0.00019 & $\mathrm{mg}$ & $\mathrm{ng}$ & 3.5 & 50 & 0 \\
\hline Ash-Weight & 0.12 & 0.06 & $\%$ & $\mathrm{ng}$ & 9.0 & 31 & 0 \\
\hline Total-Lipid & 0.003 & 0.0015 & $\%$ & $\mathrm{ng}$ & 16.6 & 39 & 0 \\
\hline
\end{tabular}

\begin{tabular}{|l|c|c|c|c|c|}
\hline Component & $\begin{array}{c}\text { rapportage- } \\
\text { grens Triskelion }\end{array}$ & unit & $\mathrm{ng} / \mathrm{dg}$ & \multicolumn{2}{c|}{$\begin{array}{c}\text { meetonzekerheid (\%) } \\
\text { Triskelion }\end{array}$} \\
\hline Cadmium & 0.0003 & $\mathrm{mg} / \mathrm{kg}$ & $\mathrm{ng}$ & $8.7 \%$ op niveau van $1.3 \mathrm{mg} / \mathrm{kg}$ \\
\hline Zink & 0.25 & $\mathrm{mg} / \mathrm{kg}$ & $\mathrm{ng}$ & $8.5 \%$ op niveau van $69 \mathrm{mg} / \mathrm{kg}$ \\
\hline Koper & 0.015 & $\mathrm{mg} / \mathrm{kg}$ & $\mathrm{ng}$ & $9.0 \%$ op niveau van $4.4 \mathrm{mg} / \mathrm{kg}$ \\
\hline Lood & 0.007 & $\mathrm{mg} / \mathrm{kg}$ & $\mathrm{ng}$ & $10 \%$ op niveau van $1.4 \mathrm{mg} / \mathrm{kg}$ \\
\hline Chroom & 0.007 & $\mathrm{mg} / \mathrm{kg}$ & $\mathrm{ng}$ & $13 \%$ op niveau van $0.065 \mathrm{mg} / \mathrm{kg}$ \\
\hline Nikkel & 0.012 & $\mathrm{mg} / \mathrm{kg}$ & $\mathrm{ng}$ & $13 \%$ op niveau van $0.2 \mathrm{mg} / \mathrm{kg}$ & 0 \\
\hline Arseen & 0.005 & $\mathrm{mg} / \mathrm{kg}$ & $\mathrm{ng}$ & $17 \%$ op niveau van $1.4 \mathrm{mg} / \mathrm{kg}$ \\
\hline
\end{tabular}

op basis van juistheidsbepaling en monsterinhomogeniteit

verwaarloosbaar klein

$\mathrm{n}=$ aantal ringonderzoeken aan de hand waarvan een Z-score bepaald kon worden

De meetonzekerheid opgegeven door Triskelion is opgebouwd uit de variatie in de lab-reproduceerbaarheid en uit de scores in

ringonderzoeken

*Meetonzekerheid gebaseerd op de RMS van juistheidbepaling en de inhomogeniteitsbijdrage van de praktijkmonsters

$\mathrm{dc}$ is de combined constant error in de eenheid van de concentratie van de component. 
